\title{
Naphthenic Acids: Formation, Role in Emulsion Stability, and Recent Advances in Mass Spectrometry-Based Analytical Methods
}

\author{
Roselaine Facanali $\mathbb{D}^{1},{ }^{1}$ Nathália de A. Porto ${ }^{D},{ }^{1}$ Juliana Crucello $\triangle{ }^{1},{ }^{1}$ Rogerio M. Carvalho, ${ }^{2}$ \\ Boniek G. Vaz, ${ }^{3}$ and Leandro W. Hantao ${ }^{1}{ }^{1}$ \\ ${ }^{1}$ Institute of Chemistry, University of Campinas, Campinas 13083-862, SP, Brazil \\ ${ }^{2}$ Leopoldo Américo Miguez de Mello Research and Development Center, Petrobras, Rio de Janeiro 20031-912, RJ, Brazil \\ ${ }^{3}$ Institute of Chemistry, Federal University of Goiás, Goiânia 74690-900, GO, Brazil \\ Correspondence should be addressed to Leandro W. Hantao; wang@unicamp.br
}

Received 6 August 2021; Accepted 24 November 2021; Published 17 December 2021

Academic Editor: Cecilia Cagliero

Copyright (c) 2021 Roselaine Facanali et al. This is an open access article distributed under the Creative Commons Attribution License, which permits unrestricted use, distribution, and reproduction in any medium, provided the original work is properly cited.

\begin{abstract}
Naphthenic acids (NAs) are compounds naturally present in most petroleum sources comprised of complex mixtures with a highly variable composition depending on their origin. Their occurrence in crude oil can cause severe corrosion problems and catalysts deactivation, decreasing oil quality and consequently impacting its productivity and economic value. NAs structures also allow them to behave as surfactants, causing the formation and stabilization of emulsions. In face of the ongoing challenge of treatment of water-in-oil (W/O) or oil-in-water $(\mathrm{O} / \mathrm{W})$ emulsions in the oil and gas industry, it is important to understand how NAs act in emulsified systems and which acids are present in the interface. Considering that, this review describes the properties of NAs, their role in the formation and stability of oil emulsions, and the modern analytical methods used for the qualitative analysis of such acids.
\end{abstract}

\section{Introduction}

In petroleum fields, crude oil and produced water (PW) emulsions are formed during oil production when the fluid undergoes flow restrictions. The inevitable emulsification of crude oil and PW may increase fluid viscosity, leading to several problems in flow assurance and primary processing. Emulsion stability is mainly determined by the structural properties of its interfacial layer [1-3].

Being among the most important surfactants naturally found in oil sources [4], naphthenic acids (NAs) comprise all petroleum-derived organic acids [5], including aromatics, tricyclic diamondoids, and sulfur-containing compounds [6]. For these compounds can migrate to water during the oil and bitumen extraction process [7], NAs are also detected in PW samples. The classes and concentration levels of NAs will vary depending on the origin of the oil [3], just as NAs and their salts may exhibit varying solubility in aqueous phases depending on their chemical structures $[8,9]$.
According to $\mathrm{pH}$ conditions and water content, acidic oils can form different types of emulsions with varying stability. However, emulsions are impacted by a multivariate and complex interplay of parameters and mechanisms, thus hindering the full comprehension of the role of NAs in stabilizing emulsions.

\section{Emulsion}

When flowing through pipes, oil and water are subjected to agitation, promoting dispersion from one phase to another and resulting in emulsions [10]. Defined as a mixture of two immiscible or partially immiscible liquids, where one liquid is dispersed in the other in the form of droplets of microscopic or colloidal size [10-12], emulsions can be found in almost all stages of the production chain, from exploration to refining [10].

Emulsions are complex structures characterized according to the liquid that forms the continuous phase [13]: 
if the continuous medium is water, the emulsion is characterized as an oil-in-water type (O/W); conversely, if the continuous medium is oil, emulsion is named water-in-oil (W/O). In more complex situations, multiple water-in-oilin-water $(\mathrm{W} / \mathrm{O} / \mathrm{W})$ or oil-in-water-in-oil $(\mathrm{O} / \mathrm{W} / \mathrm{O})$ systems are possible [10], as shown in Figure 1.

In the petroleum industry, $\mathrm{W} / \mathrm{O}$ is the most common type of emulsion formed during oil production. Such emulsions typically contain $\leq 50 \%$ of water [14]. One may also find $\mathrm{O} / \mathrm{W}$ emulsions, whose water content may be up to $\geq 80 \%$ [14].

Kinetically stable emulsions are formed in the presence of surfactants, whose hydrophilic-lipophilic balance (HLB) is the most important parameter for predicting emulsion type. For instance, while $\mathrm{O} / \mathrm{W}$ emulsions are preferably formed with hydrophilic surfactants, W/O emulsions occur in the presence of hydrophobic emulsifiers [15]. Each emulsion type has its own morphology and characteristics, being converted into another type upon a phase inversion process.

The aqueous phase contains inorganic salts such as chlorides, sulfates, and carbonates of various metals, which may contribute to the process of corrosion, incrustation formation, and catalyst deactivation [11]. Hence, demulsification processes are necessary to separate the oil phase from the aqueous phase and its associated inorganic salts [12]. Water-oil emulsion phase separation is conducted in three stages: flocculation, sedimentation, and coalescence [16].

2.1. Formation and Stability of Emulsions. Visually, emulsions are a single-phase system produced by applying shear or sufficient energy to form dispersed droplets, regardless of the oil origin $[17,18]$. However, being thermodynamically unstable, they tend to separate and return to the original two-phase condition. In this scenario, surfactants and stabilizers can make the emulsion kinetically stable for an extended period (occasionally for decades) [19]. Emulsion stability is impacted by the formation of an interfacial film around the droplets [8], which makes surface-active molecules line up at the interface, directing their hydrophilic portion to the aqueous phase and the hydrophobic portion to the oil phase. The interfacial layer formed by surfactants exhibits viscoelastic properties resistant to compression/ deformation. Emulsion stability is also related to the mobility of the emulsifying species in the interfacial film [10].

Surfactants enable emulsification by reducing interfacial tension (IT) and forming a film at the water-oil interface, slowing the flocculation and coalescence of the droplets [20]. Resins and other polar compounds are examples of naturally occurring surfactants present in oil [20-22]. However, no consensus has been reached as to the role of asphaltenes in emulsion stability [23-25]. For example, asphaltenes and NAs form a rigid and well-structured interfacial film, wherein NAs salt effectively stabilizes the emulsion, while asphaltenes contribute only to the viscoelasticity of the interfacial film [26].

Mechanisms such as steric hindrance, electrostatic repulsion, and the Gibbs-Marangoni effect may likewise affect emulsions stability [27-30]. Steric hindrance forms a barrier that prevents coalescence between droplets, thus hindering their approximation. This barrier is generally constituted by surfactant molecules adsorbed at the droplet interface [27-30]. In turn, electrostatic repulsion occurs due to the existence of ionic surfactants at the water-oil interface, responsible for the formation of an electric double layer that causes repulsion and prevents droplet collision and coalescence [31]. This type of mechanism is insignificant in $\mathrm{W} /$ $\mathrm{O}$ emulsions due to the oil low dielectric constant, thus being way more common in $\mathrm{O} / \mathrm{W}$ emulsions $[8,32]$. The Gibbs-Marangoni effect, on the other hand, occurs due to the formation of interfacial tension gradients generated by adsorbed molecules, whose presence can lead to interfacial stress gradients capable of resisting tangential stresses. In practice, the droplets of an emulsion can be deformed and resist coalescence due to the elastic film formed [8]. For occurring in conjunction with other mechanisms, the Gibbs-Marangoni effect can be considered as a secondary mechanism for stabilizing emulsions.

The presence of solid particles can also provide kinetic stability to emulsions. Although not part of oil intrinsic composition, inorganic particles can act as barriers to prevent coalescence at the water-oil interface. The efficiency of these solids in stabilizing an emulsion depends on factors such as particle size (which should be much smaller than the drop size [33]) and wettability. These solids can also be electrically charged, improving the stability of the emulsion by electrostatic repulsion $[8,10,34]$.

Inorganic solids commonly found in petroleum are derived from corrosion products (e.g., iron sulfide, oxides), mineral scale, formation sand, clay, drilling muds, and stimulation fluids. When incorporated into petroleum, these particles can aggregate with asphaltenes and resins, stabilizing emulsions $[35,36]$. These inorganic compounds may also promote emulsion stabilization by interacting synergistically with NAs [37].

Oil composition is also important for emulsion formation and stability. Crude oil is a complex mixture composed mainly of hydrocarbons, corresponding to up to $90 \%(w t)$, and organic compounds containing small amounts of sulfur, nitrogen, oxygen, and organometallics [38]. Oil fractions can be classified as saturated, aromatic, resins, and asphaltene (components of the SARA fractionation), varying in solubility and adsorptive properties [39].

Asphaltenes and resins are the most polar fractions of crude oil, accounting for the most significant impact on emulsion stability [40]. These compounds exhibit acidic and basic functionalities responsible for stabilizing W/O emulsions [41]. Asphaltenes are insoluble in aliphatic solvents such as $\mathrm{n}$-pentane and n-heptane but soluble in aromatic solvents such as toluene $[42,43]$. These substances exhibit a polyaromatic core with aliphatic side chains containing heteroatoms such as nitrogen, oxygen, and sulfur and can coordinate with metals such as nickel, vanadium, and iron $[42,43]$. Studies have shown that asphaltenes are strong stabilizers of W/O emulsions [44] and that their subfractions, called interfacially active asphaltenes, effectively contribute to emulsion stability $[8,24,25,45-50]$ by regulating the interfacial film viscoelastic properties $[8,26,51,52]$. 


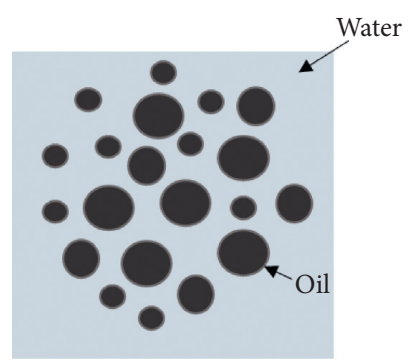

(a)

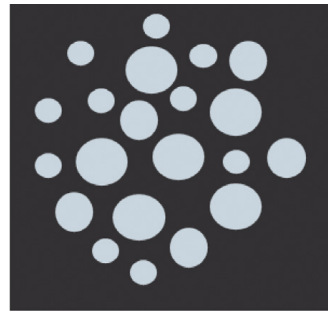

(b)

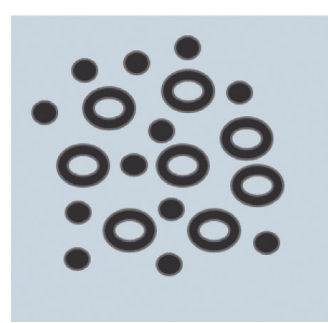

(c)

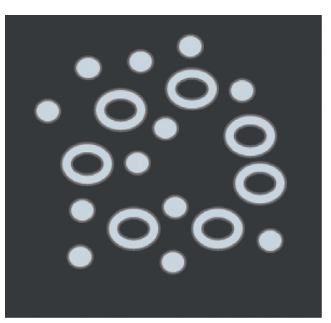

(d)

FIGURE 1: Representation of emulsions in which water is the continuous phase (a), oil is the continuous phase (b), and multiple systems (c, d). (a) Oil-in-water (O/W). (b) Water-in-oil (W/O). (c) Water-in-oil-in-water (W/O/W). (d) Oil-in-water-in-oil (O/W/O).

Asphaltenes have negligible surface activity and exhibit low emulsion stabilization when solubilized in oil [52]. These substances are estimated to first aggregate into colloidal particles, the actual interfacially active entities [53], forming asphaltenic aggregates $(7-20 \mathrm{~nm})$ that stabilize the interfacial film, thus promoting emulsion formation [54, 55]. Resins are responsible for maintaining colloidal stability by interacting with asphaltenic aggregates [56].

Resins comprehend the fraction insoluble in propane but soluble in n-pentane. They are classified as polar hydrocarbons with aliphatic characteristics but are less aromatic compared to asphaltenes. Despite having heteroatoms such as nitrogen $(\mathrm{N})$, oxygen $(\mathrm{O})$, and sulfur $(\mathrm{S})$, they do not contain metals [42]. Due to their primary surface-active properties and secondary role in stabilizing the colloidal asphaltenic aggregates, resins are considered as an important class to forming stable emulsions, a fact supported by studies that found asphaltenes as a fine powder in oils with a low resin/asphaltene ratio $[52,57]$. Other studies also suggest that resins delay asphaltenes migration onto the interface [8].

NAs are an important resin subgroup that is very effective in reducing IT [37]. Asphaltenes and NAs are present at the water-oil interface, synergistically stabilizing the emulsion by forming a viscoelastic film [37, 58, 59]. For example, the occurrence of hydrogen bonds makes the stabilization of asphaltenic aggregates with NAs likely to occur [58]. This is supported by the interfacial material characterization, which confirmed the predominance of carboxylic acids. For being also present in the asphaltene fraction, this finding suggests that asphaltene/acid films were responsible for stabilizing the emulsions $[60,61]$.

\section{Naphthenic Acids (NAs)}

NAs are naturally occurring compounds resulting from the biodegradation of petroleum, caused by bacteria or the lack of catagenesis (oil maturity level) in its deposit. Thus, NAs can be used as biomarkers and are directly related to oil maturity and biodegradation level $[62,63]$. They can be present in different concentrations depending on the extraction site, reaching values ranging from 2 to $4 \%(w t)$ on average [64]. When investigating acidic oil from West Africa, most NAs were found in the light and intermediate fractions, while the latter fraction contained the NAs with the most surface activity [65]. NAs can also be found in PW in dissolved and dispersed forms, that is, as oil droplets [66].

NAs consist of a mixture of linear- and branched-chains carboxylic acids and cyclic substituents [67]. The carboxyl group can occur directly bonded to the naphthenic structure or in the side chain, being separated by " $\mathrm{CH}_{\Sigma}$ " units [68]. Figure 2 shows the general structures of NAs, where $\mathrm{m}$ represents the number of “ $\mathrm{CH}_{2}$ " units and $R$ the aliphatic group [69].

The general chemical formula of an NA is $\mathrm{C}_{n} \mathrm{H}_{2 n}+{ }_{Z} \mathrm{O}_{x}$, where $n$ indicates the number of carbons, $Z$ refers to the hydrogen deficiency due to cyclic structures, and $x$ is the number of oxygens in the molecule $[5,70,71]$. The $Z$ value is related to the double bond equivalent (DBE) value, as shown by equations (1) and (2) [72], where $C$ is the number of carbon atoms, $\mathrm{H}$ is the number of hydrogen atoms, and $\mathrm{N}$ is the number of nitrogen atoms of the molecule. Each element index in equation (1) is based on the element valence. Considering the general formula, the carbon index is $[0.5 \times(4-2)]=+1$, the hydrogen index is $[0.5 \times(1-2)]=$ 0.5 , and the nitrogen index is $[0.5 \times(3-2)]=+0.5$. For the oxygen, the resulting index will be zero: $[0.5 \times(2-2)]=0$.

$$
\begin{aligned}
\mathrm{DBE} & =1+\mathrm{C}-\frac{\mathrm{H}}{2}+\frac{\mathrm{N}}{2}, \\
Z & =-2 \times \mathrm{DBE}+2 .
\end{aligned}
$$

The $Z$ value is traditionally used for the qualitative analysis of NAs, indicating the presence of cyclic moieties such as acyclic $(Z=0)$, monocyclic $(Z=-2)$, bicyclic $(Z=-4)$, tricyclic $(Z=-6)$, and tetracyclic $(Z=-8)$ acids [73]. Cyclopentyl- and cyclohexyl-based acids $(Z=-2)$ are the predominant structures commonly detected in oils, corresponding to approximately $95 \%$ of the NA composition. Conversely, the acids most found in oil sands process-affected water (OSPW) have $2(\mathrm{Z}=-4)$ or 3 $(\mathrm{Z}=-6)$ condensed rings $[74,75]$. In $\mathrm{PW}$, monocyclic acids are the main structures with $n$ values of 7 to 12 carbons [76], and in OSPW the $n$ and $Z$ values range from 7 to 30 and from -12 to 0 , respectively $[67,75,77]$. NA fraction can consist of hundreds of homologs and their isomers, thus posing an analytical challenge for qualitative and quantitative studies. 


$$
\mathrm{Z}=0 \quad \mathrm{CH}_{3}\left(\mathrm{CH}_{2}\right)_{\mathrm{m}} \mathrm{COOH}
$$

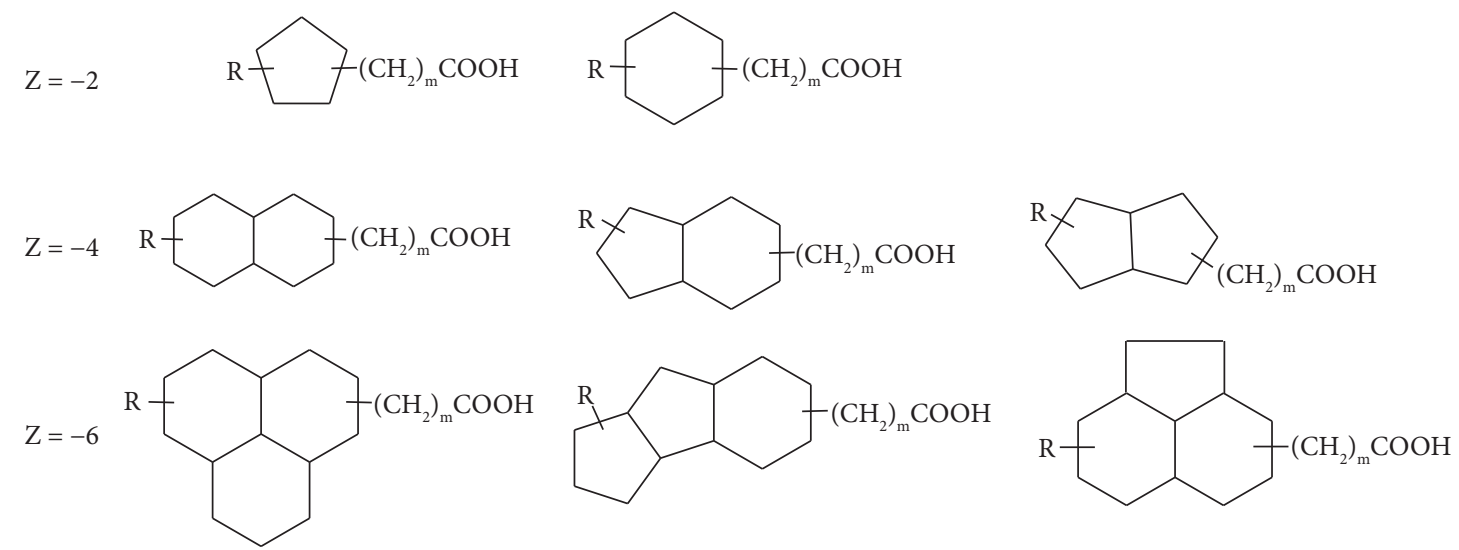

Figure 2: Typical naphthenic acid structure. The $Z$ value refers to the hydrogen deficiency, $R$ represents an alkyl substitute, and $m$ represents the carbon chain size.

Although physical properties of NAs depend heavily on their chemical structure, average trends are provided for illustrative purposes. NAs and their sodium salts are generally water-soluble [62], but heavier homologs can precipitate under certain conditions. Smaller NAs are soluble in the aqueous

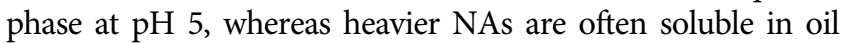
phase; heavier NAs become soluble in aqueous phase at higher $\mathrm{pH}$ values $[8,9]$. These compounds' average density is between 0.97 and $0.99 \mathrm{~g} / \mathrm{cm}^{3}$ [76] , and their dissociation constant (pKa) ranges from 5 to 6 depending on the acid structure (for comparison purposes, the acetic acid and propionic acid exhibit pKa values of 4.7 and 4.9 , respectively). NAs viscosity depends on the oil grade, being typically set between 40 and $100 \mathrm{mPa} \cdot \mathrm{s}$ [78]. Moreover, these compounds exhibit low volatility, with Henry constants close to $8.56 \times 10^{-6} \mathrm{~atm} \cdot \mathrm{m}^{3} / \mathrm{mol}$ and vapor pressure of approximately $2.35 \times 10^{-6} \mathrm{~atm}$, and their boiling point ranges between 250 and $350^{\circ} \mathrm{C}$ [79].

NAs are the class that most contributes to petroleum acidity [3]. The acid level is commonly measured in terms of total acid number (TAN) and expressed in milligrams of potassium hydroxide per gram of sample (mg KOH/g). Acidity can be measured by two different methods: the potentiometric (i.e., ASTM D664) and colorimetric protocols (i.e., ASTM D974) [80], with TAN values $\geq 0.5 \mathrm{mg} \mathrm{KOH} / \mathrm{g}$ indicating high acidity [81]. The fact that oils with similar TAN values exhibited significantly different NA profiles is justified by the compositional complexity of NAs [82].

Besides being directly related to emulsion stability [65], NAs can also aid in foam formation in operational units and in the leaching of cations such as $\mathrm{Ca}^{2+}$ and $\mathrm{Na}^{+}$ during the desalination process, which can deactivate catalysts [83]. Despite their harmful effects on the oil refining process and on the environment, pure NAs and naphthenate salts are important raw materials in the chemical industry $[69,84]$.

\section{Role of NAs in Stabilizing Emulsions}

NAs play a major role in stabilizing emulsions [85], depending on the nature and distribution of the species, aqueous phase $\mathrm{pH}$, and oil composition. Some studies have shown that smaller NAs are the most effective in regulating IT [86], while larger NAs stabilize emulsion by secondary mechanisms [12]. Systems formed by NAs/naphthenates/ water produce the D-phase, composed of lyotropic liquid crystals. These aggregates are microstructures formed by several layers of surfactant and water, and their presence disproportionately increases emulsions stability $[8,31]$.

The ionic nature of the NAs significantly influences the emulsion interfacial properties [8]. When compared with neutral acids, the anionic state of acids has a more considerable impact on IT reduction [8], an effect related to the Donnan equilibrium, which occurs with an inversion of the solubility of the surface-active molecules from oil-soluble to water-soluble [87].

A study verified that $\mathrm{W} / \mathrm{O}$ emulsion was predominant in the $6.5-14 \mathrm{pH}$ range and $10.30-50 \%$ water contents $(\mathrm{w} / \mathrm{w})$ [65]. In turn, $\mathrm{O} / \mathrm{W}$ emulsions predominantly occurred in a narrow high-stability region with $50 \%(\mathrm{w} / \mathrm{w})$ water content and $\mathrm{pH}$ value between 12 and 13.5. NAs are found as naphthenates in $\mathrm{pH}$ values above 13 , suggesting that $\mathrm{O} / \mathrm{W}$ emulsions stability was secured by electrostatic repulsions between naphthenates present at the interface. Conversely, $\mathrm{W} / \mathrm{O}$ emulsions stability is due to the asphaltenes and resins present in the heavy fraction of the oil [65].

The composition of NAs in $\mathrm{pH}$-modulated interactions between NAs and asphaltenes was evaluated using a low TAN value oil [60]. Hydrophilic naphthenic and aromatic monoacids contributed to gel formation and promoted stable emulsions, whereas hydrophobic naphthenic and aromatic monoacids were insignificant to emulsion stabilization. Fatty acids adsorbed in paraffins formed a rigid interface. However, 
at neutral $\mathrm{pH}$, these species competed with asphaltenes at the emulsion interface, thus decreasing the stability. Diprotic acids adsorbed at the interface and favored asphaltenes adsorption, producing very compact emulsions [60]. This finding was corroborated by yet another study, which found diprotic NAs and asphaltenes to form integrated films with high dilatational elasticity [61]. Following the same trend, a new method for isolating interfacial material (IM) revealed that interfacially active species comprised oxygenated acids and sulfur-containing compounds [45], and acidic compounds isolated from bitumen IM indicated the presence of $\mathrm{O}_{3} \mathrm{~S}_{1}, \mathrm{O}_{2}$, and $\mathrm{O}_{4}$ species occurring as monoacids and diacids [88].

$\mathrm{O} / \mathrm{W}$ emulsions were also found to be stabilized by a synergistic effect of the combination of the surfactant and the $\mathrm{C}_{20}-\mathrm{C}_{30}$ carboxylate salts in an alkalis/surfactant/polymer system with $\mathrm{pH}>8$ [89]. In general, two types of naphthenates can be formed: calcium and sodium naphthenates. Whereas calcium naphthenates are present as solid deposits at the water/oil interface, sodium naphthenates promote emulsion stabilization [90]. The type of naphthenate formed will be determined by chemical nature of the NA [91], with calcium naphthenates being often associated with the presence of the tetraprotic naphthenic acid (ARN).

ARN are a class of tetraprotic NAs that are typically found in low oil concentrations ( 0.6 to $3.6 \mathrm{ppm})[92,93]$. These acids include 4 to 8 rings in their structure, with the most abundant containing 6 rings with the molecular formula $\mathrm{C}_{80} \mathrm{H}_{142} \mathrm{O}_{8}$ (Figure 3). ARN is the predominant class of acids in calcium naphthenate deposits $[92,93]$. The interaction of an ARN monolayer with calcium ions results in more robust and less soluble interfacial film, reducing its compressibility and promoting emulsion stability. ARN also exhibits dynamic selfassociation, producing elastic and solid films [94]. When compared with crystalline sodium naphthenates, calcium naphthenates form amorphous solids [94].

ARN preferably forms $\mathrm{O} / \mathrm{W}$ emulsions with water content ranging from 10 to $90 \%(\mathrm{v} / \mathrm{v})$ and $\mathrm{pH}$ interval from 4 to 10 [95]. The maximum emulsion stability was attained using intermediate water content and alkaline conditions. Moreover, $\mathrm{NaCl}$ and $\mathrm{CaCl}_{2}$ influenced the type of emulsion, whereby $\mathrm{NaCl}$ addition caused a phase inversion from $\mathrm{O} / \mathrm{W}$ to W/O by increasing ARN affinity towards the oil phase. However, excessive concentrations of $\mathrm{NaCl}$ decreased emulsion stability. $\mathrm{Ca}^{2+}$ addition resulted in no phase inversion.

Besides the aforementioned conditions, the presence of other divalent cations $\left(\mathrm{Mg}^{2+}, \mathrm{Ca}^{2+}, \mathrm{Sr}^{2+}\right.$, and $\left.\mathrm{Ba}^{2+}\right)$ decreased IT value due to the electrostatic attraction between cations in the aqueous phase and the naphthenates at the oil/water interface. This led to a higher density of NAs at the interface and the formation of positively charged monoacid complexes, which present high interfacial activity $[96,97]$.

Another study also evaluated the synergistic behavior of naphthenate-asphaltene mixtures [98]. The competitive adsorption at the oil/water interface between naphthenates and asphaltenes was described by two layers, in which naphthenates occupied the primary layer, reducing IT and controlling surface morphology, while asphaltenes were predominant in the secondary (or "floating") layer.

\section{NAs Techniques and Characterization}

NAs consist of hundreds of different compounds, with more than one isomer for each $n$ and $Z$ value or compound class, making the separation and individual analysis of NA a difficult task [67]. A single mixture, for example, contains over 1,500 different NAs with a broad range of molar mass (up to 1,500 Da) [99-101]. Moreover, some species are detected at trace levels [88], requiring a preconcentration step prior to instrumental analysis. Numerous studies employed liquid-liquid (LLE) and solid-phase extraction (SPE) to extract NAs $[88,89,102]$, but LLE was the most popular method. Sample preparation methods are vital for analyzing NAs by direct MS, enabling selective characterization and reducing ionic suppression effects $[64,103]$.

Over recent years, MS-based qualitative analysis became the most efficient analytical tool for the molecular analysis of NAs. As long as the mass spectrometer exhibits sufficient resolution and accuracy to provide reliable measurements of the monoisotopic mass and its corresponding isotopic patterns, any MS-based method can practically achieve group-type separation $[64,67,75,77,99]$. In this context, the direct-MS analysis offers an ideal platform for highthroughput experimentation, even though the analysis of individual compositional isomers and diastereomers may be jeopardized. Regarding diastereomers, hyphenated methods such as gas (GC-MS) and liquid chromatography (LC-MS) coupled to mass spectrometry are interesting alternatives for differentiating and quantifying isomers due to the improved chromatographic resolution and reduced matrix effect [102, 104-106].

5.1. Gas Chromatography-Based Methods. Gas chromatography (GC) is an instrumental technique widely used to separate mixtures based on the vapor pressure and solvation parameters of their composing molecules [107]. GC-MS is the most ubiquitous analytical technique for identifying and quantifying small organic substances in complex matrices [108]. Performed under high vacuum, electron ionization (EI) and chemical ionization (CI) are the standard ionization methods for GC-MS, being the most sensitive and robust analytical techniques. In theory, EI produces an odd-electron molecular ion $\left(\left[\mathrm{M}^{+}\right]\right)$for detecting the nominal or monoisotopic mass [109]; however, the molecular ion stability depends heavily on the molecule chemical structure, so that not all molecules exhibit such an ion. Molecules with lower ionization energies tend to produce more stable molecular ions. Ionization energy increases in the following order: nonbonding electrons $<\pi$ electrons $<\sigma$ electrons. Hence, aromatic NAs will exhibit more intense peaks of the molecular ion compared to linear organic acids. Due to the excess of internal energy, molecular ion generation is also accompanied by fragmentation, thus making the EI spectrum energy-dependent. Furthermore, the EI mass spectrum is information-rich and reproducible, allowing for mass spectral databases.

An interesting approach to improve molecular ion detection is analyte derivatization. Pseudomolecular ions are 


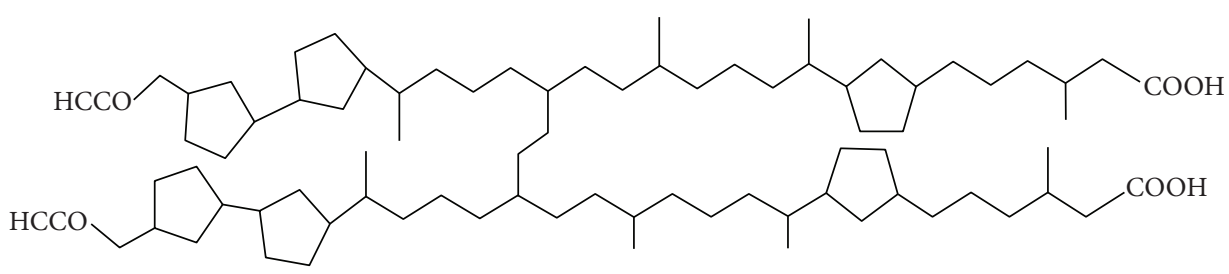

Figure 3: Chemical structure of tetraacid $\mathrm{C}_{80}(\mathrm{ARN})$.

available when using silylation reactions, yielding the evenelectron $[\mathrm{M}-15]^{+}$and $[\mathrm{M}-57]^{+}$ions. Derivatization with $\mathrm{N}$ methyl- $N$-( $t$-butyldimethylsilyl)trifluoroacetamide

(MTBSTFA) generates $t$-butyldimethylsilylated ( $t$-BDMS) acids, which produce stable $[\mathrm{M}-57]^{+}$ions, where $M$ represents the molecular mass of the derivatized acid [104]. Such pseudomolecular ions can be used for putative identification of the NAs, as shown in Table 1, where the $[\mathrm{M}-57]^{+}$nominal mass is proposed based on the general formula $\mathrm{C}_{n} \mathrm{H}_{2 n}{ }^{-} \mathrm{Z} \mathrm{O}_{2}$ for alicyclic monocarboxylic acids [102]. Moreover, derivation methods such as methylation, acylation, and silylation [110-112] are used to increase analyte volatility and improve peak symmetry when using poly(dimethyl-diphenylsiloxane)-based GC stationary phases.

Although incipient in such applications, positive chemical ionization (PCI) is an interesting alternative for GC-MS analysis of NAs. PCI uses methane or ammonia as reagent gas, which provides soft ionization and generates the adduct ion $\left([\mathrm{M}+\mathrm{H}]^{+}\right)$depending on the analyte nature. For allowing an unequivocal detection of the adduct ion and its corresponding nominal (or monoisotopic) mass and isotopic pattern, PCI is an interesting method for assigning the elemental composition of complex mixtures.

GC-MS methods have been used to characterize NAs due to the hyphenated technique improved peak capacity $[67,75,102,113-117]$. In a single run, a study managed to identify 156 NAs by GC-MS [67]. Similarly, when investigating the acidic fraction isolated from heavy gas oil of Marlim petroleum (Brazil) by GC-MS, another study detected alicyclic naphthenic acids with up to four rings $(Z=-8)$ [102]. Authors also found NAs with carbon numbers ranging from 5 to 26 and $Z$ values of 0 to -10 in marine sediments, with acyclic $(Z=0)$ and monocyclic carboxylic acids $(Z=-2)$ with 12 to 19 carbons being the predominant NAs classes, corresponding to $>70 \%$ of the total. Dicyclic- $(Z=-4)$, tricyclic- $(Z=-6)$, and tetracyclic $(Z=-8)$ carboxylic acids were also reported by GC-MS analysis [115]. A different study found more than 100 NAs from OSPW, verifying extensive peak overlap with hydrocarbons [118], an unresolved complex mixture (UCM) also reported elsewhere [102, 117, 119].

To improve NA analysis, GC was coupled to Fourier transform ion cyclotron resonance (GC-FT-ICR MS) with different ionization methods, EI, CI, and atmospheric pressure chemical ionization (APCI) $[120,121]$. Methane and ammonia were used as reagent gases [121], providing complementary information to previously reported methods. EI evidenced the pronounced UCM due to the occurrence of hydrocarbons, while CI improved the detection of $\mathrm{N}$-containing species. Kendrick mass defect plots showed that $\mathrm{O}$ and $\mathrm{O}_{2}$ were among the most abundant classes, but $\mathrm{HC}, \mathrm{S}, \mathrm{SO}, \mathrm{SO}_{2}, \mathrm{O}_{3}, \mathrm{O}_{4}, \mathrm{~N}, \mathrm{NO}, \mathrm{NO}_{2}$, and $\mathrm{NO}_{3}$ were also present [120]. These results illustrate the potential of GC-MS analysis of NAs using high-resolution and accurate mass measurements to improve the molecular coverage of GC-based methods.

In this context, comprehensive two-dimensional gas chromatography $(\mathrm{GC} \times \mathrm{GC})$ is an interesting alternative for analyzing NAs in complex samples. This technique combines two sequential GC separation steps in a single analysis by using columns with complementary solvation properties [122-124]. Compared to conventional gas chromatography (1D-GC), GC $\times$ GC provides improved peak capacity [125], as shown in Figures 4(a) and 4(b). Moreover, such method performs group-type analysis of NAs more readily due to the structured chromatogram, wherein homologous series exhibit unique elution patterns.

GC $\times$ GC-MS has significantly improved the chromatographic resolution of NAs [126], facilitating the structural elucidation of individual isomers [6, 127-131]. The first GC $\times$ GC application dates from 2005, in commercial mixtures and bituminous sand samples, indicating acyclic and monocyclic acids containing one and two saturated rings [126]. The structured chromatogram allowed assigning identities according to the analyte $Z$ value [132]. Two technical mixtures were evaluated (Sigma-Aldrich and Miracema-Nuodex), verifying the presence of NAs with $Z=0,-2,-4$, and -6 . More specifically, the carbon number of bicyclic acids $(Z=-4)$ ranged from 9 to 16 [132]. Furthermore, an extensive series of tricyclic diamondoid acids and bicyclic, tricyclic, and pentacyclic diacids have been identified in OSPW $[6,127-131]$. The distribution of diamondoid acid methyl esters was used to differentiate OSPW samples, also indicating their potential as petroleum markers [131]. NAs identification relied on the comparison of retention times and mass spectra with model compounds, but the use of retention indices is recommended to improve identification reliability.

Different classes of compounds have been identified in OSPW using GC $\times$ GC-MS. The identified carboxylic acids include indane, tetralin, cyclohexane, and adamantane [133]. Another work identified isomers of individual bicyclic aromatic acids in petroleum fractions using their methyl ester derivatives, suggesting that acids may be biotransformation products and indicative of bacterial processes occurring in reservoirs [134]. Other studies also confirmed the structures of some NAs of "nontraditional" chemical classes with reference standards, such as thiophene carboxylic acid $\left(\mathrm{SO}_{2}\right.$ 
TABLE 1: Expected even-electron ions $\left([\mathrm{M}-57]^{+}\right)$for homologous series of $t$-butyldimethylsilylated naphthenic acids [104].

\begin{tabular}{|c|c|c|c|c|c|c|c|}
\hline \multirow{2}{*}{ Carbon number $(n)$} & \multicolumn{7}{|c|}{ Nominal mass for $[\mathrm{M}-57]^{+}$ion } \\
\hline & $Z=0$ & $Z=-2$ & $Z=-4$ & $Z=-6$ & $Z=-8$ & $Z=-10$ & $Z=-12$ \\
\hline 6 & 173 & 171 & - & - & - & - & - \\
\hline 7 & 187 & 185 & - & - & - & - & - \\
\hline 8 & 201 & 199 & - & - & - & - & - \\
\hline 9 & 215 & 213 & 211 & - & - & - & - \\
\hline 10 & 229 & 227 & 225 & - & - & - & - \\
\hline 11 & 243 & 241 & 239 & - & - & - & - \\
\hline 12 & 257 & 255 & 253 & 251 & - & - & - \\
\hline 13 & 271 & 269 & 267 & 265 & - & - & - \\
\hline 14 & 285 & 283 & 281 & 279 & - & - & - \\
\hline 15 & 299 & 297 & 295 & 293 & 291 & - & - \\
\hline 16 & 313 & 311 & 309 & 307 & 305 & - & - \\
\hline 17 & 327 & 325 & 323 & 321 & 319 & - & - \\
\hline 18 & 341 & 339 & 337 & 335 & 333 & 331 & 329 \\
\hline 19 & 355 & 353 & 351 & 349 & 347 & 345 & 343 \\
\hline 20 & 369 & 367 & 365 & 363 & 361 & 359 & 357 \\
\hline 21 & 383 & 381 & 379 & 377 & 375 & 373 & 371 \\
\hline 22 & 397 & 395 & 393 & 391 & 389 & 387 & 385 \\
\hline 23 & 411 & 409 & 407 & 405 & 403 & 401 & 399 \\
\hline 24 & 425 & 423 & 421 & 419 & 417 & 415 & 413 \\
\hline 25 & 439 & 437 & 435 & 433 & 431 & 429 & 427 \\
\hline 26 & 453 & 451 & 449 & 447 & 445 & 443 & 441 \\
\hline 27 & 467 & 465 & 463 & 461 & 459 & 457 & 455 \\
\hline 28 & 481 & 479 & 477 & 475 & 473 & 471 & 469 \\
\hline 29 & 495 & 493 & 491 & 489 & 487 & 485 & 483 \\
\hline 30 & 509 & 507 & 505 & 503 & 501 & 499 & 497 \\
\hline 31 & 523 & 521 & 519 & 517 & 515 & 513 & 511 \\
\hline 32 & 537 & 535 & 533 & 531 & 529 & 527 & 525 \\
\hline 33 & 551 & 549 & 547 & 545 & 543 & 541 & 539 \\
\hline
\end{tabular}

class) [133] and diamondoid dicarboxylic acids $\left(\mathrm{O}_{4}\right.$ class) [127]. Identifying sulfur species is very useful for predicting and understanding the corrosion caused by NAs [133], while diacids formation in PW is probably due to late actions of the natural biodegradation on the corresponding monoacid $[127,133]$. In another report, GC $\times$ GC-MS was used to monitor specific isomers of NAs in three geochemically distinct zones [135], successfully identifying a collection of acids like monocyclic, bicyclic, adamantane, and thiophene carboxylic (alkylated).

5.2. Liquid Chromatography-Based Methods. Liquid chromatography (LC) is a well-suited technique for analyzing polar analytes in complex samples, complementing the molecular coverage of GC-based methods. LC is considered extremely versatile by enabling multiple separation modes, such as normal phase (NP), reversed phase (RP), and hydrophilic interaction chromatography (HILIC) [136]. The most common ambient ionization methods in LC-MS are electrospray ionization (ESI), APCI, and atmospheric pressure photoionization (APPI). Among these, ESI is the most common ionization method used for NAs analysis by LC-MS, producing the even-electron $[\mathrm{M}+\mathrm{H}]^{+}$or $[\mathrm{M}-\mathrm{H}]^{-}$ adduct ions $[105,137,138]$. Elemental analysis depends on the purity of the measured monoisotopic mass and its fine isotopic pattern. For instance, mass resolving powers of approximately 60,000 (at $m / z 200$ ) and $120,000($ at $m / z 400)$ are required to resolve isobaric doublets with a mass difference of only $3.4 \mathrm{mDa}$ [139].

Several studies in the literature have applied LC-MS, thus providing important information on NAs. This technique has been used, for example, for analyzing oxy-NAs (i.e., $\mathrm{O}_{2}$, $\mathrm{O}_{3}$, and $\mathrm{O}_{4}$ ) in OSPW samples [106], whereby $\mathrm{O}_{2-}, \mathrm{O}_{3-}$, and $\mathrm{O}_{4}$ classes accounted for $33.6 \%$ of total organic matter extracted. The results indicate that adding oxygen atoms in the molecules increased their $\mathrm{pKa}$ values, while double bonds and aromatic components reduced pKa values [106]. LC-MS was also applied to routine methods for quantitative analysis of classical NAs and oxy-NAs [105]. In this study, LC reduced ion suppression five-fold when compared with direct MS analysis, besides verifying significant variations in the response factors among the model NAs compounds [105]. Another approach employed LC coupled to sequential mass spectrometry (LC-MS/MS) [138, 140], thus allowing to resolve isomers based on retention time and the quantitation of individual NAs [140]. To improve (3-fold) and normalize NAs response factors, NAs were derivatized with $\mathrm{N}$-(3dimethylaminopropyl)- $N^{\prime}$-ethylcarbodimide (EDC). The precursor ion scan was used to monitor the common product ion of the EDC derivatives, regardless of the original structure of the NA [138].

Analyzing NAs in OSPW samples by LC-MS shows that NAs concentration decreased after coke and ozone treatments. NAs structures were mainly composed of analytes with carbon number from 12 to 16 and $Z$ values from -4 to 


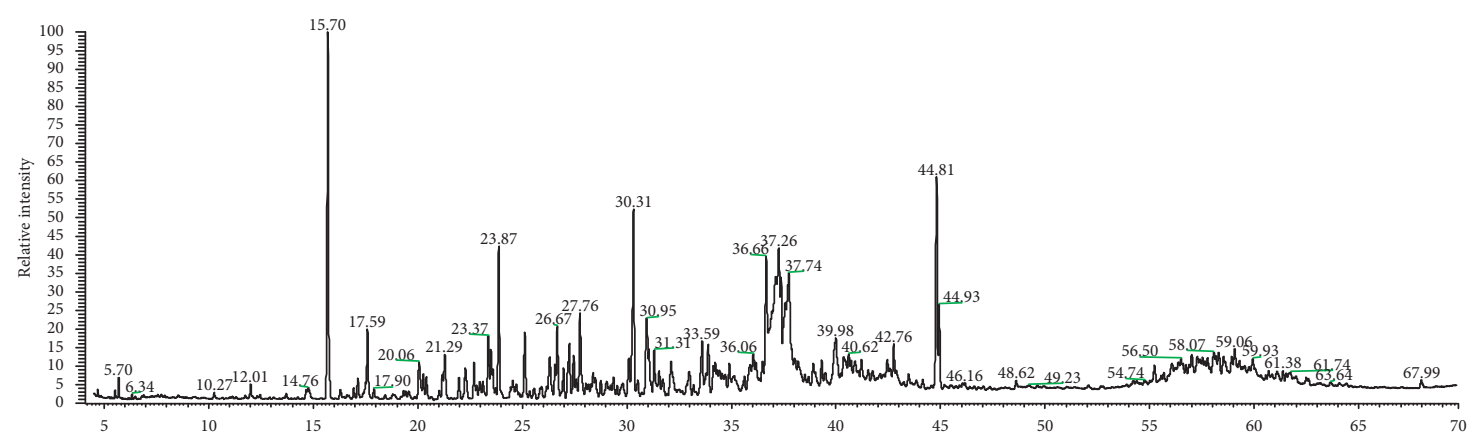

(a)

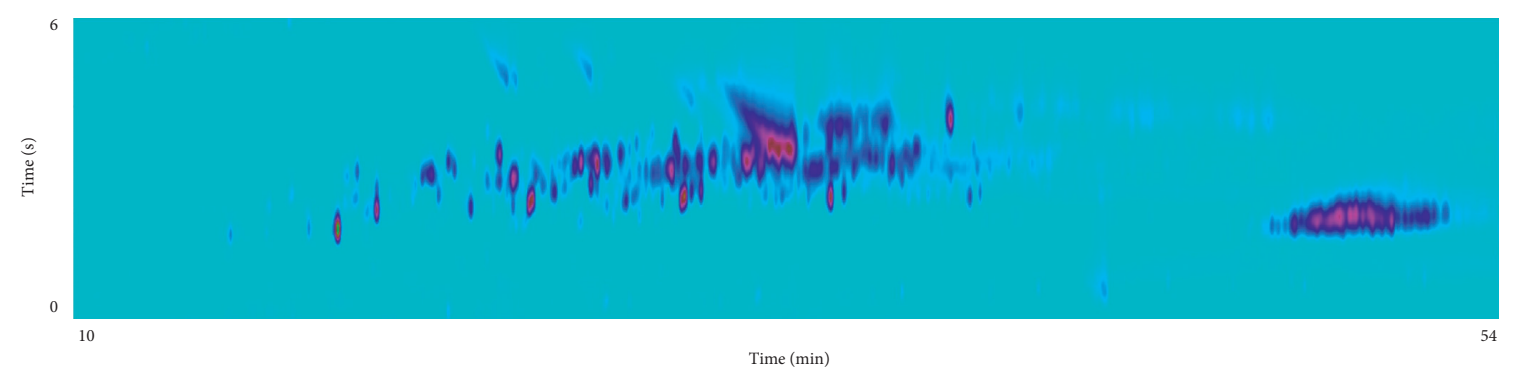

(b)

FIGURE 4: NAs chromatograms in simulated produced water sample obtained by GC-MS (a) and GC×GC-MS (b). GC analyses were performed on a TRACE1310 gas chromatograph coupled to a fast-scanning ISQ single transmission quadrupole mass spectrometer (Thermo Fisher Scientific, Waltham, MA, USA). For GC-MS, a $30 \mathrm{~m} \times 0.25 \mathrm{~mm}$-di (film thickness of $0.25 \mu \mathrm{m}$ ) Equity 1701 capillary column was used. The carrier gas was helium at a constant flow of $1.0 \mathrm{~mL} \cdot \mathrm{min}^{-1} ; 2.0 \mu \mathrm{l}$ of the sample was injected into a $250^{\circ} \mathrm{C}$ spitless injector. The oven temperature was set from $50^{\circ} \mathrm{C}$ to $260^{\circ} \mathrm{C}$ at $2 \mathrm{~min}^{-1}$. The ion source and transfer line were kept at $275^{\circ} \mathrm{C}$ and $260^{\circ} \mathrm{C}$, respectively. Electron ionization (EI) was performed at $70 \mathrm{eV}$. Mass range was set from 35 to $350 \mathrm{Da}$ at $6 \mathrm{scans} \mathrm{s}^{-1}$. For GC $\times \mathrm{GC}-\mathrm{MS}$, the first-dimension column was a $20 \mathrm{~m} \times 0.18 \mathrm{~mm}$-di $(0.18 \mu \mathrm{m}$ film thickness $)$ SLB-1MS capillary column and the second-dimension column was a $5 \mathrm{~m} \times 0.25 \mathrm{~mm}$-di $\left(0.25 \mu \mathrm{m}\right.$ film thickness) OV 1701 capillary column. The injector was operated in split mode with a $1: 10$ split ratio, at $250^{\circ} \mathrm{C}$. Helium was used as carrier and auxiliary gas at constant flow rate of 0.5 and $20.0 \mathrm{~mL} \cdot \mathrm{min}^{-1}$. Modulation period was set to $6 \mathrm{~s}$ with a $400 \mathrm{~ms}$ reinjection (flush) pulse. The oven temperature was set from $50^{\circ} \mathrm{C}$ to $265^{\circ} \mathrm{C}$ at $5^{\circ} \mathrm{C} \cdot \mathrm{min}^{-1}$. Ion source and transfer line were kept at $275^{\circ} \mathrm{C}$ and $260^{\circ} \mathrm{C}$, respectively. Mass range was set from 40 to $350 \mathrm{Da}$ at $15 \mathrm{scans} \mathrm{s}^{-1}$.

-8 , with only some NAs with carbon number above 18 [141]. Another study detected 55 unique NAs isomer groups in PW samples from different Norwegian offshore oil platforms with carbon number ranging from 8 to 26 and $Z$ values of 0 to -18 . Based on NAs distribution and the concentration in the samples, the $\mathrm{C}_{8} \mathrm{H}_{14} \mathrm{O}_{2}$ isomer group appeared to be an indicator of the presence of NAs in the samples [142].

A study conducted with wastewater samples collected from different wastewater treatment plants of petroleum refineries found NAs with $Z$ values from 0 to -14 and carbon number from 10 to 20, with NAs with $Z=-2$ and -4 being the most abundant. Concentrations ranged from 113 to $392 \mu \mathrm{g} / \mathrm{L}$, with aromatic NAs estimated at 2 to $8 \%$. Upon biological treatment, total NAs decreased by $65 \%$ and aromatic NAs by $86 \%$. The removal mechanism for alicyclic and aromatic NAs was biodegradation via activated sludge, and polycyclic species NAs classes were recalcitrant to degradation [143].

LC-MS was used to characterize NAs in crude oils and refined petroleum products [144], verifying NAs with $Z$ values ranging from -2 to -24 and carbon number from 6 to 60 , among which those with $Z=-2$ to -6 were the most abundant. $\mathrm{O}_{2}$ was the most intense class among NAs, accounting for about half of the total acid component of the studied oils. In turn, $\mathrm{O}_{4}$ and $\mathrm{O}_{6}$ (presumably dicarboxylic and tricarboxylic acids) were observed only at very low abundances when compared with $\mathrm{O}_{2}$. Saturated carboxylic acids $(Z=0)$ were also detected in all studied samples in considerable concentrations [144]. In another study conducted with OSPW samples from marshy aquatic environments, NAs molecular characterization demonstrated $\mathrm{O}_{2}, \mathrm{O}_{3}, \mathrm{O}_{4}, \mathrm{O}_{5}, \mathrm{O}_{6}, \mathrm{~S}, \mathrm{O}_{2} \mathrm{~S}, \mathrm{O}_{3} \mathrm{~S}, \mathrm{O}_{4} \mathrm{~S}$, and $\mathrm{O}_{5} \mathrm{~S}$ classes. Within this sample, $\mathrm{O}_{x}(x \geq 2)$ was the predominant species, accounting for more than $90 \%$ of the total abundance, followed by $\mathrm{O}_{\mathrm{x}} \mathrm{S}$. Nitrogen-containing species were detected in very low abundance $(\leq 0.4 \%)$ [145].

A different study used LC-MS to characterize samples of surface mining OSPW and in situ OSPW [146], finding the main classes of compounds to be $\mathrm{O}_{1-6}, \mathrm{~N}, \mathrm{NO}_{1-4}, \mathrm{~S}, \mathrm{SO}_{1-4}$, and $\mathrm{NO}_{2} \mathrm{~S}$. Class distributions were similar in both OSPW samples, but surface mining samples had higher prevalence of $\mathrm{O}_{1-6}$ species, while in situ samples showed relatively more $\mathrm{N}, \mathrm{NO}_{1-4}$, $\mathrm{S}, \mathrm{SO}_{1-4}$, and $\mathrm{NO}_{2} \mathrm{~S}$ species. MS/MS experiments revealed that the $\mathrm{O}_{2}$ class included nonacidic compounds with dihydroxy, diketo, or ketohydroxy moieties [146]. In a subsequent study, the distinction between $\mathrm{O}_{2}$ species was performed in ozonated OSPW samples [147], obtaining a molecular profile information for $\mathrm{O}_{x}$ and $\mathrm{SO}_{x}$ species that indicated that species 
detected in ESI (+) mode were more recalcitrant to ozonation than those detected in ESI (-) ionization mode. The study highlighted the importance of using more than one ionization mode to improve molecular coverage, particularly for characterizing NAs by LC-MS [147].

A polar fraction of OSPW was used to assess the composition of NAs with LC-MS [148], whereby $\mathrm{SO}_{3}$ and $\mathrm{SO}_{5}$ species were the major classes detected by APCI (+). $\mathrm{O}_{2}$ class compounds with carbon number from 16 to 18 and DBE equal to 6 were the most prevalent, along with $\mathrm{O}_{4}$ classes, which are mainly bicyclic and tricyclic nonaromatic species, probably comprising mainly unesterified diacids with carbon number from 18 to 24 [148].

5.3. Direct Mass Spectrometry-Based Method. Direct MS analysis is possible by high-resolution mass analyzers such as FT-ICR MS and electrostatic ion trap with Fourier transform (FT-Orbitrap MS). Fourier transform-based MS instruments are key for petroleomics research, offering unprecedented mass resolving power and reliable compositional analysis [149]. More specifically, FT-ICR MS and FTOrbitrap MS have outperformed contemporary time of flight-based MS instruments due to the achievable resolution and mass accuracy, even when a reduced number of ions is detected [150]. For example, an FT-Orbitrap MS was successfully used in NAs analysis, allowing for reliable grouptype and semiquantitative analysis [151]. Another study endeavored to compare the performance of a compact highfield FT-Orbitrap MS to that of a gold-standard FT-ICR MS instrument, reporting similar compositional results in the FT-Orbitrap MS with average mass accuracies below $1 \mathrm{ppm}$ [152]. Similarly, the FT-Orbitrap MS and FT-ICR MS were used for qualitative analysis of polar compounds in crude oil [153], finding the most abundant species in both instruments to be $\mathrm{N}, \mathrm{N}_{2}, \mathrm{O}_{3}, \mathrm{O}_{1}, \mathrm{O}_{2}, \mathrm{NO}_{2}$, NS, and OS classes. While $\mathrm{O}_{2}$ class showed higher relative abundance in the FT-Orbitrap MS, the other classes were detected in lower proportions compared to FT-ICR MS [153].

The most common ionization methods for direct MS analysis include ESI [154], APCI [148], and APPI [155]. Such direct MS approach is also more prone to matrix effects, requiring careful sample preparation by online or offline fractionation depending on the complexity of the sample [156].

Before selecting the ionization method, one must carefully consider the desired classes of analytes to be measured. ESI is highly suitable for studying polar compounds containing heteroatoms, such as NAs [64]. Different studies have classified NAs from calcium and sodium naphthenate deposits by ESI (-)-FT-ICR MS [91, 154], verifying that sodium naphthenate deposits contained mainly linear saturated monoprotic $\mathrm{NAs}\left(\mathrm{C}_{15}\right.$ to $\left.\mathrm{C}_{35}\right)$, while calcium naphthenate deposits consisted mainly of ARN acids $\left(\mathrm{C}_{80}\right)$, besides including also smaller species of ARN $\left(\mathrm{C}_{60}-\mathrm{C}_{70}\right)$. Another study identified similar trends in crude oil samples from South America [93]. Moreover, APPI has been successfully used for the ionization of aliphatic and aromatic hydrocarbons [157], thus indicating that the combination of ESI and APPI can be used to provide complementary information about NAs classes in complex samples [155]. APPI allowed the ionization of additional compounds that were not detected by ESI, such as hydrocarbons, $S_{1}$ and $N_{1}$ [155]. When applied to the analysis of NAs from OSPW samples [71], APPI likewise enabled the identification of different classes that were not detected by ESI, such as hydrocarbons, $\mathrm{N}_{1} \mathrm{O}_{1}, \mathrm{~N}_{1} \mathrm{O}_{2}, \mathrm{~N}_{1} \mathrm{O}_{3}, \mathrm{~N}_{1} \mathrm{O}_{4}, \mathrm{~N}_{1} \mathrm{O}_{5}$, $\mathrm{N}_{2} \mathrm{O}_{1}, \mathrm{~N}_{2} \mathrm{O}_{2}$, and $\mathrm{N}_{2} \mathrm{O}_{3}$. In negative mode (-), APPI also detected $\mathrm{O}_{5}, \mathrm{O}_{6}, \mathrm{O}_{7}$, and $\mathrm{S}_{1} \mathrm{O}_{4}$. Regarding $\mathrm{O}_{2}$ class, APPI (-) exhibited the same classes as ESI [71].

For enabling selective characterization and reducing the effects of ionic suppression, sample preparation methods are vital for the analysis of NAs by direct MS. In this context, FTICR MS was used to characterize NAs fractions in OSPW samples extracted with different solvents, namely, cyclohexane, dichloromethane, $n$-hexane, and cyclohexane: butyl acetate [103]. The solvent mixture cyclohexane: butyl acetate was the most effective, extracting a wide array of oxygencontaining species $\left(\mathrm{O}_{x}, \mathrm{SO}_{x}\right.$, and $\left.\mathrm{NO}_{x}\right)$ and enabling the extraction of hydrocarbon species with five or more oxygen atoms. Compared to other solvents, the cyclohexane: butyl acetate mixture allowed the detection of NAs with a wider range of DBE values and carbon number and oxygencontaining classes up to $\mathrm{O}_{9}$, while $\mathrm{n}$-hexane and cyclohexane extracted classes of compounds up to $\mathrm{O}_{5}$. Similar trends were observed for $\mathrm{SO}_{x}$ and $\mathrm{NO}_{x}$, suggesting that cyclohexane: butyl acetate was more efficient than $\mathrm{n}$-hexane and cyclohexane for extracting polar compounds [103].

A study conducted with NAs present in a thermally degraded oil evaluated liquid-liquid extraction (LLE) and solid-phase extraction (SPE), finding SPE to allow the detection of a larger range of NAs species $(\mathrm{m} / z$ 200-1200), thus reducing the suppression of ions with higher molecular mass $(m / z$ 700-1200 Da) [64]. LLE with hydroalcoholic alkaline solutions was also used to extract NAs that contributed to TAN variation. FT-ICR MS indicated species with less than 44 carbons and DBE values ranging from 3 to 4 , suggesting chemical structures with a carboxylic acid and up to three naphthenic rings. Polar acidic species $\left(\mathrm{O}_{2}\right.$ class), nitrogencontaining compounds, and $\mathrm{NO}_{2}$ compounds were also detected [158].

SPE and LLE were also evaluated under acidic and basic conditions to profile OSPW samples by FT-Orbitrap MS [159]. Oxygen-containing compounds (i.e., $\mathrm{O}_{1-6}$ ) were the most prevalent in acid extracts, especially $\mathrm{O}_{4}$. When extracted under basic conditions, classical NAs $\left(\mathrm{O}_{2}\right)$ exhibited the highest intensity (ranging from 30 to $44 \%$ ). A different study employed FT-Orbitrap MS to evaluate different solvents and SPE phases for the extraction of NAs in OSPW [160], verifying that NAs distribution depends on the extraction solvent/polarity. Hexane-based extraction was found to provide a more selective extraction of $\mathrm{O}_{2}$ species when compared with other solvents, such as chloroform and ethyl acetate. These findings indicate that, when comparing results from a sample, one must necessarily standardize the analytical method by employing the same extraction procedure.

Isolation of interfacial material requires dedicated sample preparation methods, such as fractionation using a modified aminopropyl silica (MAPS). FT-ICR MS analyses 
of interfacially active materials isolated by MAPS revealed a high abundance of low molecular weight molecules. All fractions presented $\mathrm{O}_{3} \mathrm{~S}_{1}, \mathrm{O}_{2}$, and $\mathrm{O}_{4}$ species, as both monocharged and double-charged acids [88]. A study proposed a new isolation method for interfacial material, known as "wet silica," revealing that isolated species contained an abundance of oxygen- and sulfur-containing compounds when compared with crude oil [45]. A compositional analysis by FT-ICR MS in an alkalis/surfactant/ polymer system showed the presence of carboxylic acids, pyrroles, and phenols using MAPS and "wet silica" for the isolation of interfacial material [89].

Lastly, chemometric methods can be used to process compositional data, enabling the recognition of useful patterns and establishment of predictive models. For example, in a study conducted with partial least squares regression to estimate the TAN value of Brazilian crude oils $[101,161]$, most modelled compounds belonged to $\mathrm{N}$ and $\mathrm{O}_{2}$ classes, suggesting that $\mathrm{O}_{2}$ compounds were the main contributors to the observed TAN values. Such approaches are particularly interesting for highly complex mixtures, providing important information that may be disregarded in univariate analysis due to the high amount of data generated by high-resolution MS.

\section{Concluding Remarks}

This review showed that the stability of water-oil emulsions is related to the interfacial film formed between the continuous and the dispersed phases. To the best of our knowledge, the literature still lacks reports addressing oilwaters systems. Interface stability is improved by the occurrence of surface-active compounds naturally present in petroleum, where NAs are among the most important classes. NAs play an important role in the stability of oil emulsions by reducing the system interfacial tension according to the nature and distribution of NAs, among other factors. In this context, the development of reliable analytical methods for the qualitative and quantitative analysis of NAs is extremely necessary for improving our understanding of these compounds and their occurrence in crude oils. NAs composition is highly variable and depends on the oil source. To introduce the available solutions, significant developments using hyphenated MS methods and direct MS approaches were presented in this study, which also discussed basic aspects of sample preparation and data processing that accompany GC-MS, LC-MS, and MS.

We hope this review will raise awareness as to the existing challenges for improving our understanding on naphthenic acids. Despite the major advances in analytical methods for NAs, the elucidation of all NAs remains a critical research requirement. Such advances and their application to study naphthenic acids may provide a starting point for developing standard quantitative methods for characterizing NAs.

\section{Data Availability}

No data were used to support the findings of this study.

\section{Conflicts of Interest}

The authors declare that they have no conflicts of interest.

\section{Acknowledgments}

This study was financed by the ANP/Petrobras (Grant no. 2019/00209-3), the National Council for Scientific and Technological Development (CNPq, Grant no. 302748/20180 ), the São Paulo Research Foundation (FAPESP, Grant no. 2020/01064-6), and the Coordination for the Improvement of Higher Education Personnel (CAPES) (Finance CODE 001). The authors would like to thank the Espaço da EscritaPró-Reitoria de Pesquisa-UNICAMP for the language services provided.

\section{References}

[1] S. Zhang, L. Zhang, X. Lu et al., "Adsorption kinetics of asphaltenes at oil/water interface: effects of concentration and temperature," Fuel, vol. 212, pp. 387-394, 2018.

[2] P. M. Spiecker and P. K. Kilpatrick, "Interfacial rheology of petroleum asphaltenes at the oil-water interface," Langmuir, vol. 20, no. 10, pp. 4022-4032, 2004.

[3] B. S. Rana, D.-W. Cho, K. Cho, and J.-N. Kim, “Total Acid Number (TAN) reduction of high acidic crude oil by catalytic esterification of naphthenic acids in fixed-bed continuous flow reactor," Fuel, vol. 231, pp. 271-280, 2018.

[4] L. L. Schramm, E. N. Stasiuk, and M. MacKinnon, "Surfactants in athabasca oil sands slurry conditioning, flotation recovery, and tailings processes," in Surfactants, pp. 365-430, Cambridge University Press, Cambridge, UK, 2000.

[5] A. Bertheussen, S. Simon, and J. Sjöblom, "Equilibrium partitioning of naphthenic acid mixture, part 1: commercial naphthenic acid mixture," Energy \& Fuels, vol. 32, no. 7, pp. 7519-7538, 2018.

[6] S. J. Rowland, A. G. Scarlett, D. Jones, C. E. West, and R. A. Frank, "Diamonds in the rough: identification of individual naphthenic acids in oil sands process water," Environmental Science \& Technology, vol. 45, no. 7, pp. 3154-3159, 2011.

[7] S. A. Hughes, R. Huang, A. Mahaffey et al., "Comparison of methods for determination of total oil sands-derived naphthenic acids in water samples," Chemosphere, vol. 187, pp. 376-384, 2017.

[8] J. Sjöblom, N. Aske, I. Harald, Ø. Brandal, T. Erik, and $\emptyset$. Sæther, "Our current understanding of water-in-crude oil recent characterization techniques and high pressure performance," vol. 102, pp. 399-473, 2003.

[9] A. Goldszal, M. Bourrel, M. Hurtevent, and J. L. Volle, "Stability of water in acidic crude oil emulsions," in Proceedings of the Third International Conference on Petroleum Phase Behavior and Fouling New Orleans, LA, USA, 2002.

[10] S. L. Kokal, "Crude oil emulsions: a state-of-the-art review," SPE Production and Facilities, vol. 20, no. 1, pp. 5-13, 2005.

[11] A. M. Araujo, L. M. Santos, M. Fortuny, R. L. F. V. Melo, R. C. C. Coutinho, and A. F. Santos, "Evaluation of water content and average droplet size in water-in-crude oil emulsions by means of near-infrared spectroscopy," Energy \& Fuels, vol. 22, no. 5, pp. 3450-3458, 2008.

[12] M. A. Saad, M. Kamil, N. H. Abdurahman, R. M. Yunus, and O. I. Awad, "An overview of recent advances in state-of-the- 
art techniques in the demulsification of crude oil emulsions," Processes, vol. 7, no. 7, p. 470, 2019.

[13] L. L. Schramm, Emulsions, Foams, and Suspensions: Fundamentals and Applications, Wiley, Weinheim, Germany, 2005.

[14] D. R. Salomon, Asphalt Emulsion Technology, TRC E-102, Transportation Research Board, Washington, DC, USA, 2006.

[15] F. Leal-Calderon and V. Schmitt, "Solid-stabilized emulsions," Current Opinion in Colloid \& Interface Science, vol. 13, no. 4, pp. 217-227, 2008.

[16] B. F. Graham, E. F. May, and R. D. Trengove, "Emulsion inhibiting components in crude oils," Energy \& Fuels, vol. 22, no. 2, pp. 1093-1099, 2008.

[17] P. L. Bansbach, "Treating emulsions produced by thermal recovery operation," in Proceedings of the SPE California Regional Meeting, Bakersfield, CA, USA, November 1965.

[18] K. E. Arnold and H. Smith, "Crude oil emulsions," in Petroleum Engineering Handbook, H. B. Bradley and F. W. Gipson, Eds., Society of Petroleum Engineers, Texas, TX, USA, 1992.

[19] S. S. Dukhin, J. Sjöblom, and Ø. Sæther, “An experimental and theoretical approach to the dynamic behavior of emulsions," in Emulsions and Emulsion Stability: Surfactant Science Series, J. Sjöblom, Ed., pp. 1-101, CRC Press, Boca Raton, FL, USA, 2nd edition, 2005.

[20] L. L. Schramm, "Petroleum emulsions," Advances in Chemistry, vol. 231, pp. 1-49, 1992.

[21] R. E. P. Cunha, M. Fortuny, C. Dariva, and A. F. Santos, "Mathematical modeling of the destabilization of crude oil emulsions using population balance equation," Industrial \& Engineering Chemistry Research, vol. 47, no. 18, pp. 70947103, 2008.

[22] R. F. Lee, "Agents which promote and stabilize water-in-oil emulsions," Spill Science \& Technology Bulletin, vol. 5, no. 2, pp. 117-126, 1999.

[23] R. Varadaraj and C. Brons, "Molecular origins of crude oil interfacial activity part 3: characterization of the complex fluid rag layer formed at crude oil-water interfaces," Energy \& Fuels, vol. 21, no. 3, pp. 1617-1621, 2007.

[24] J. Czarnecki and K. Moran, "On the stabilization mechanism of water-in-oil emulsions in petroleum systems," Energy \& Fuels, vol. 19, no. 5, pp. 2074-2079, 2005.

[25] J. Czarnecki, "Stabilization of water in crude oil emulsions. part 2," Energy \& Fuels, vol. 23, no. 3, pp. 1253-1257, 2009.

[26] S. F. Wong, J. S. Lim, and S. S. Dol, "Crude oil emulsion: a review on formation, classification and stability of water-inoil emulsions," Journal of Petroleum Science and Engineering, vol. 135, pp. 498-504, 2015.

[27] R. C. C. Coutinho, J. C. Pinto, M. Nele, A. Hannisdal, and J. Sjöblom, "Evaluation of water-in-crude-oil emulsion stability using critical electric field: effect of emulsion preparation procedure and crude oil properties," Journal of Dispersion Science and Technology, vol. 32, no. 7, pp. 923934, 2011.

[28] C. Dicharry, D. Arla, A. Sinquin, A. Graciaa, and P. Bouriat, "Stability of water/crude oil emulsions based on interfacial dilatational rheology," Journal of Colloid and Interface Science, vol. 297, no. 2, pp. 785-791, 2006.

[29] F. Martínez-Boza, P. Partal, B. Conde, and C. Gallegos, "Influence of temperature and composition on the linear viscoelastic properties of synthetic binders," Energy \& Fuels, vol. 14, pp. 131-137, 2000.
[30] C. B. Z. de Oliveira, W. J. Souza, C. F. Santana et al., "Rheological properties of water-in-Brazilian crude oil emulsions: effect of water content, salinity, and $\mathrm{pH}$," Energy \& Fuels, vol. 32, no. 8, pp. 8880-8890, 2018.

[31] D. Daltin, Tensoativos: Química, Propriedades e Aplicações, 1a Reimpre, Editora Edgard Blücher, São Paulo, Brazil, 2011.

[32] T. E. Havre and J. Sjöblom, "Emulsion stabilization by means of combined surfactant multilayer (D-phase) and asphaltene particles," Colloids and Surfaces A: Physicochemical and Engineering Aspects, vol. 228, no. 1-3, pp. 131-142, 2003.

[33] D. M. Sztukowski and H. W. Yarranton, "Oilfield solids and water-in-oil emulsion stability," Journal of Colloid and Interface Science, vol. 285, no. 2, pp. 821-833, 2005.

[34] D. Tambe, J. Paulis, and M. M. Sharma, "Factors controlling the stability of colloid-stabilized emulsions," Journal of Colloid and Interface Science, vol. 171, no. 2, pp. 463-469, 1995.

[35] I. Kralova, J. Sjöblom, G. Øye, S. Simon, B. A. Grimes, and K. Paso, "Heavy crude oils/particle stabilized emulsions," Advances in Colloid and Interface Science, vol. 169, no. 2, pp. 106-127, 2011.

[36] T. Al-Sahhaf, A. Elsharkawy, and M. Fahim, "Stability of water-in-crude oil emulsions: effect of oil aromaticity, resins to asphaltene ratio, and $\mathrm{pH}$ of water," Petroleum Science and Technology, vol. 26, no. 17, pp. 2009-2022, 2008.

[37] R. Varadaraj and C. Brons, "Molecular origins of heavy crude oil interfacial activity part 2: fundamental interfacial properties of model naphthenic acids and naphthenic acids separated from heavy crude oils," Energy \& Fuels, vol. 21, no. 1, pp. 199-204, 2007.

[38] C. E. Perles, V. C. B. Guersoni, and A. C. Bannwart, "Rheological study of crude oil/water interface - the effect of temperature and brine on interfacial film," Journal of Petroleum Science and Engineering, vol. 162, pp. 835-843, 2018.

[39] S. A. Raya, I. Mohd Saaid, A. Abbas Ahmed, and A. Abubakar Umar, "A critical review of development and demulsification mechanisms of crude oil emulsion in the petroleum industry," Journal of Petroleum Exploration and Production Technology, vol. 10, no. 4, pp. 1711-1728, 2020.

[40] C. B. Kabbach and R. G. dos Santos, "Effects of pH and temperature on the phase behavior and properties of asphaltene liquid films," Energy \& Fuels, vol. 32, no. 3, pp. 2811-2818, 2018.

[41] D. Subramanian, N. May, and A. Firoozabadi, "Functional molecules and the stability of water-in-crude oil emulsions," Energy \& Fuels, vol. 31, no. 9, pp. 8967-8977, 2017.

[42] J. G. Speight, "Petroleum asphaltenes - Part 1: asphaltenes, resins and the structure of petroleum," Oil and Gas Science and Technology, vol. 59, no. 5, pp. 467-477, 2004.

[43] O. C. Mullins, "The asphaltenes," Annual Review of Analytical Chemistry, vol. 4, no. 1, pp. 393-418, 2011.

[44] J. P. Rane, V. Pauchard, A. Couzis, and S. Banerjee, "Interfacial rheology of asphaltenes at oil-water interfaces and interpretation of the equation of state," Langmuir, vol. 29, no. 15, pp. 4750-4759, 2013.

[45] J. M. Jarvis, W. K. Robbins, Y. E. Corilo, and R. P. Rodgers, "Novel method to isolate interfacial material," Energy \& Fuels, vol. 29, no. 11, pp. 7058-7064, 2015.

[46] P. Kilpatrick and P. Matthew Spiecker, "Asphaltene emulsions," in Encyclopedic Handbook of Emulsion Technology, M. Dekker, Ed., CRC Press, New York, NY, USA, pp. 707-730, 2001. 
[47] M. D. Lobato, F. Gámez, S. Lago, and J. M. Pedrosa, "The influence of the polarity of fractionated asphaltenes on their Langmuir-film properties," Fuel, vol. 200, pp. 162-170, 2017.

[48] X. Wu, "Investigating the stability mechanism of water-indiluted bitumen emulsions through isolation and characterization of the stabilizing materials at the interface," Energy \& Fuels, vol. 17, no. 1, pp. 179-190, 2003.

[49] F. Yang, P. Tchoukov, E. Pensini et al., "Asphaltene subfractions responsible for stabilizing water-in-crude oil emulsions. Part 1: interfacial behaviors," Energy \& Fuels, vol. 28, no. 11, pp. 6897-6904, 2014.

[50] N. Zaki, P.-C. Schoriing, and I. Rahimian, "Effect of asphaltene and resins on the stability of water-in-waxy oil emulsions," Petroleum Science and Technology, vol. 18, no. 78, pp. 945-963, 2000.

[51] J. Sjöblom, P. V. Hemmingsen, and H. Kallevik, "The role of asphaltenes in stabilizing water-in-crude oil emulsions," in Asphaltenes, Heavy Oils, and Petroleomics, pp. 549-587, Springer, New York, NY, USA, 2007.

[52] J. D. McLean and P. K. Kilpatrick, "Effects of asphaltene solvency on stability of water-in-crude-oil emulsions," Journal of Colloid and Interface Science, vol. 189, no. 2, pp. 242-253, 1997.

[53] S. Singh, J. D. McLean, and P. K. Kilpatrick, "Fused ring aromatic solvency in destabilizing water-in-asphalteneheptane-toluene emulsions," Journal of Dispersion Science and Technology, vol. 20, no. 1-2, pp. 279-293, 1999.

[54] P. K. Kilpatrick, "Water-in-crude oil emulsion stabilization: review and unanswered questions," Energy \& Fuels, vol. 26, no. 7, pp. 4017-4026, 2012.

[55] Y. Fan, S. Simon, and J. Sjöblom, "Interfacial shear rheology of asphaltenes at oil-water interface and its relation to emulsion stability: influence of concentration, solvent aromaticity and nonionic surfactant," Colloids and Surfaces A: Physicochemical and Engineering Aspects, vol. 366, no. 1-3, pp. 120-128, 2010.

[56] J. D. McLean and P. K. Kilpatrick, "Effects of asphaltene aggregation in model heptane-toluene mixtures on stability of water-in-oil emulsions," Journal of Colloid and Interface Science, vol. 196, no. 1, pp. 23-34, 1997.

[57] R. Pal, "Effect of droplet size on the rheology of emulsions," AIChE Journal, vol. 42, no. 11, pp. 3181-3190, 1996.

[58] R. Varadaraj and C. Brons, "Molecular origins of heavy oil interfacial activity part 1: fundamental interfacial properties of asphaltenes derived from heavy crude oils and their correlation to chemical composition," Energy \& Fuels, vol. 21, no. 1, pp. 195-198, 2007.

[59] X. Yang and J. Czarnecki, "Tracing sodium naphthenate in asphaltenes precipitated from athabasca bitumen," Energy \& Fuels, vol. 19, no. 6, pp. 2455-2459, 2005.

[60] V. Pauchard, J. Sjöblom, S. Kokal et al., "Role of naphthenic acids in emulsion tightness for a low-total-acid-number (TAN)/high-asphaltenes oil," Energy \& Fuels, vol. 23, no. 3, pp. 1269-1279, 2009.

[61] H. Muller, V. O. Pauchard, and A. A. Hajji, "Role of naphthenic acids in emulsion tightness for a low total acid number (TAN)/high asphaltenes oil: characterization of the interfacial chemistry," Energy \& Fuels, vol. 23, no. 3, pp. 1280-1288, 2009.

[62] J. S. Clemente and P. M. Fedorak, "A review of the occurrence, analyses, toxicity, and biodegradation of naphthenic acids," Chemosphere, vol. 60, no. 5, pp. 585-600, 2005.

[63] G. Rousseau, H. Zhou, and C. Hurtevent, "Calcium carbonate and naphthenate mixed scale in deep-offshore fields," in Proceedings of the International Symposium on Oilfield Scale, January 2001.

[64] E. V. Barros, H. P. Dias, F. E. Pinto et al., "Characterization of naphthenic acids in thermally degraded petroleum by ESI(-)-FT-ICR MS and 1H NMR after solid-phase extraction and liquid/liquid extraction," Energy \& Fuels, vol. 32, no. 3, pp. 2878-2888, 2018.

[65] D. Arla, A. Sinquin, T. Palermo, C. Hurtevent, A. Graciaa, and C. Dicharry, "Influence of $\mathrm{pH}$ and water content on the type and stability of acidic crude oil emulsions," Energy \& Fuels, vol. 21, no. 3, pp. 1337-1342, 2007.

[66] C. Wu, A. De Visscher, and I. D. Gates, "On naphthenic acids removal from crude oil and oil sands process-affected water," Fuel, vol. 253, pp. 1229-1246, 2019.

[67] F. Holowenko, M. D. MacKinnon, and P. M. Fedorak, "Characterization of naphthenic acids in oil sands wastewaters by gas chromatography-mass spectrometry," Water Research, vol. 36, no. 11, pp. 2843-2855, 2002.

[68] V. G. Gaikar and D. Maiti, "Adsorptive recovery of naphthenic acids using ion-exchange resins," Reactive and Functional Polymers, vol. 31, no. 2, pp. 155-164, 1996.

[69] L. D. A. Gruber, F. C. Damasceno, E. B. Caramão, R. A. Jacques, A. M. Geller, and M. C. V. d. Campos, "Ácidos naftênicos no petróleo," Química Nova, vol. 35, no. 7, pp. 1423-1433, 2012.

[70] A. Bertheussen, S. Simon, and J. Sjöblom, "Equilibrium partitioning of naphthenic acid mixture Part 2: crude oilextracted naphthenic acids," Energy \& Fuels, vol. 32, no. 9, pp. 9142-9158, 2018.

[71] J. V. Headley, K. M. Peru, M. H. Mohamed et al., "Atmospheric pressure photoionization fourier transform ion cyclotron resonance mass spectrometry characterization of tunable carbohydrate-based materials for sorption of oil sands naphthenic acids," Energy \& Fuels, vol. 28, no. 3, pp. 1611-1616, 2014.

[72] A. G. Marshall and R. P. Rodgers, "Petroleomics: chemistry of the underworld," Proceedings of the National Academy of Sciences, vol. 105, no. 47, pp. 18090-18095, 2008.

[73] J. A. Brient, P. J. Wessner, and M. N. Doyle, "Naphthenic acids," in Kirk-Othmer Encyclopedia of Chemical TechnologyJohn Wiley \& Sons, Hoboken, NJ, USA, 2000.

[74] L. F. Del Rio, A. K. M. Hadwin, L. J. Pinto, M. D. MacKinnon, and M. M. Moore, "Degradation of naphthenic acids by sediment micro-organisms," Journal of Applied Microbiology, vol. 101, no. 5, pp. 1049-1061, 2006.

[75] J. S. Clemente, N. G. N. Prasad, M. D. MacKinnon, and P. M. Fedorak, "A statistical comparison of naphthenic acids characterized by gas chromatography-mass spectrometry," Chemosphere, vol. 50, no. 10, pp. 1265-1274, 2003.

[76] J. A. Brient, P. J. Wessner, and M. N. Doyle, "Naphthenic acids," Kirk-Othmer Encyclopedia of Chemical Technology, John Wiley \& Sons, Hoboken, NJ, USA, 1995.

[77] S. Zhu, M. Li, and M. Gamal El-Din, "The roles of $\mathrm{pH}$ and draw solute on forward osmosis process treating aqueous naphthenic acids," Journal of Membrane Science, vol. 549, pp. 456-465, 2018.

[78] C. Whitby, Microbial Naphthenic Acid Degradation, Elsevier, Amsterdam, Netherlands, 1st edition, 2010.

[79] P. R. Kannel and T. Y. Gan, "Naphthenic acids degradation and toxicity mitigation in tailings wastewater systems and aquatic environments: a review," Journal of Environmental Science and Health, Part A, vol. 47, no. 1, pp. 1-21, 2012.

[80] M. M. Ramirez-Corredores, "Acidity in crude oils: naphthenic acids and naphthenates," in The Science and 
Technology of Unconventional Oils, pp. 295-385, Elsevier, Amsterdam, Netherlands, 2017.

[81] A. Zhang, Q. Ma, K. Wang, X. Liu, P. Shuler, and Y. Tang, "Naphthenic acid removal from crude oil through catalytic decarboxylation on magnesium oxide," Applied Catalysis A: General, vol. 303, no. 1, pp. 103-109, 2006.

[82] J. A. Brient, "Preprints/American Chemical Society, Division of Petroleum Chemistry: general papers and symposia," American Chemical Society, vol. 43, p. 131, 1998.

[83] S. Nasir Shah, L. Kallidanthiyil Chellappan, G. Gonfa, M. I. A. Mutalib, R. B. M. Pilus, and M. A. Bustam, "Extraction of naphthenic acid from highly acidic oil using phenolate based ionic liquids," Chemical Engineering Journal, vol. 284, pp. 487-493, 2016.

[84] Y. Wang, Z. Chu, B. Qiu, C. Liu, and Y. Zhang, "Removal of naphthenic acids from a vacuum fraction oil with an ammonia solution of ethylene glycol," Fuel, vol. 85, no. 17-18, pp. 2489-2493, 2006.

[85] J.-M. Bai, W.-Y. Fan, G.-Z. Nan, S.-P. Li, and B.-S. Yu, "Influence of interaction between heavy oil components and petroleum sulfonate on the oil-water interfacial tension," Journal of Dispersion Science and Technology, vol. 31, no. 4, pp. 551-556, 2010.

[86] J. Wen, J. Zhang, Z. Wang, and Y. Zhang, "Correlations between emulsification behaviors of crude oil-water systems and crude oil compositions," Journal of Petroleum Science and Engineering, vol. 146, pp. 1-9, 2016.

[87] J. F. Danielli, "The relations between surface $\mathrm{pH}$, ion concentrations and interfacial tension," Proceedings of the Royal Society of London. Series B-Biological Sciences, vol. 122, pp. 155-174, 1937.

[88] A. C. Clingenpeel, S. M. Rowland, Y. E. Corilo, P. Zito, and R. P. Rodgers, "Fractionation of interfacial material reveals a continuum of acidic species that contribute to stable emulsion formation," Energy \& Fuels, vol. 31, no. 6, pp. 5933-5939, 2017.

[89] J. A. Orrego-Ruiz, C. F. Medina-Sandoval, C. C. Hinds, Á. Álvaro Villar-García, and F. A. Rojas-Ruiz, "FT-ICR MS determination of the role of naphthenic acids on the stabilization of alkali/surfactant/polymer emulsified effluents: a field study," Journal of Petroleum Science and Engineering, vol. 179, pp. 192-198, 2019.

[90] J. N. Bertelli, R. M. M. Dip, R. V. Pires, F. C. Albuquerque, and E. F. Lucas, "Shear rheology using de noüy ring to evaluate formation and inhibition of calcium naphthenate at the water/oil interface," Energy \& Fuels, vol. 28, no. 3, pp. 1726-1735, 2014.

[91] M. M. Mapolelo, L. A. Stanford, R. P. Rodgers et al., "Chemical speciation of calcium and sodium naphthenate deposits by electrospray ionization FT-ICR mass spectrometry," Energy \& Fuels, vol. 23, no. 1, pp. 349-355, 2009.

[92] D. Nichols, F. Rosario, M. Bezerra, S. Gorringe, H. Williams, and G. Graham, "Calcium naphthenates in complex production systems-evaluation and chemical inhibition challenges. SPE-169756-MS," in Proceedings of the SPE International Oilfield Scale Conference and Exhibition, Aberdeen, Scotland, 2014.

[93] P. Juyal, M. M. Mapolelo, A. Yen, R. P. Rodgers, and S. J. Allenson, "Identification of calcium naphthenate deposition in South American oil fields," Energy \& Fuels, vol. 29, no. 4, pp. 2342-2350, 2015.

[94] H. Magnusson, A. M. D. Hanneseth, and J. Sjöblom, "Characterization of C80 naphthenic acid and its calcium naphthenate," Journal of Dispersion Science and Technology, vol. 29, no. 3, pp. 464-473, 2008.

[95] A.-M. D. Hanneseth, C. Selsbak, and J. Sjöblom, "Behavior and stability of naphthenic acid/naphthenate stabilized emulsions. mixed c80-tetraacid and stearic acid stabilization," Journal of Dispersion Science and Technology, vol. 31, no. 6, pp. 770-779, 2010.

[96] Ø. Brandal, A.-M. D. Hanneseth, and J. Sjöblom, "Interactions between synthetic and indigenous naphthenic acids and divalent cations across oil-water interfaces: effects of addition of oil-soluble non-ionic surfactants," Colloid \& Polymer Science, vol. 284, no. 2, pp. 124-133, 2005.

[97] Ø. Brandal and J. Sjöblom, "Interfacial behavior of naphthenic acids and multivalent cations in systems with oil and water. II: formation and stability of metal naphthenate films at oil-water interfaces," Journal of Dispersion Science and Technology, vol. 26, no. 1, pp. 53-58, 2005.

[98] X. A. Wu and J. Czarnecki, "Modeling diluted Bitumen-Water interfacial compositions using a thermodynamic approach," Energy \& Fuels, vol. 19, no. 4, pp. 1353-1359, 2005.

[99] M. P. Barrow, K. M. Peru, D. W. McMartin, and J. V. Headley, "Effects of extraction $\mathrm{pH}$ on the fourier transform ion cyclotron resonance mass spectrometry profiles of athabasca oil sands process water," Energy \& Fuels, vol. 30, no. 5, pp. 3615-3621, 2016.

[100] L. B. Moura, R. F. Guimarães, H. F. G. d. Abreu, H. C. d. Miranda, and S. S. M. Tavares, "Naphthenic corrosion resistance, mechanical properties and microstructure evolution of experimental Cr-Mo steels with high Mo content," Materials Research, vol. 15, no. 2, pp. 277-284, 2012.

[101] L. A. Terra, P. R. Filgueiras, L. V. Tose et al., "Petroleomics by electrospray ionization FT-ICR mass spectrometry coupled to partial least squares with variable selection methods: prediction of the total acid number of crude oils," The Analyst, vol. 139, no. 19, pp. 4908-4916, 2014.

[102] M. C. Vaz de Campos, E. C. Oliveira, P. J. S. Filho, C. M. S. Piatnicki, and E. B. Caramão, "Analysis of tertbutyldimethylsilyl derivatives in heavy gas oil from brazilian naphthenic acids by gas chromatography coupled to mass spectrometry with electron impact ionization," Journal of Chromatography A, vol. 1105, no. 1-2, pp. 95-105, 2006.

[103] A. T. Lewis, T. N. Tekavec, J. M. Jarvis et al., "Evaluation of the extraction method and characterization of water-soluble organics from produced water by fourier transform ion cyclotron resonance mass spectrometry," Energy \& Fuels, vol. 27, no. 4, pp. 1846-1855, 2013.

[104] W. P. St. John, J. Rughani, S. A. Green, and G. D. McGinnis, "Analysis and characterization of naphthenic acids by gas chromatography-electron impact mass spectrometry of tert.butyldimethylsilyl derivatives," Journal of Chromatography A, vol. 807, no. 2, pp. 241-251, 1998.

[105] R. Hindle, M. Noestheden, K. Peru, and J. Headley, "Quantitative analysis of naphthenic acids in water by liquid chromatography-accurate mass time-of-flight mass spectrometry," Journal of Chromatography A, vol. 1286, pp. 166-174, 2013.

[106] R. Huang, N. Sun, P. Chelme-Ayala, K. N. McPhedran, M. Changalov, and M. Gamal El-Din, "Fractionation of oil sands-process affected water using $\mathrm{pH}$-dependent extractions: a study of dissociation constants for naphthenic acids species," Chemosphere, vol. 127, pp. 291-296, 2015. 
[107] K. D. Bartle and P. Myers, "History of gas chromatography," TrAC Trends in Analytical Chemistry, vol. 21, no. 9-10, pp. 547-557, 2002.

[108] O. D. Sparkman, Z. E. Penton, and F. G. Kitson, "Introduction and history," in Gas Chromatography and Mass Spectrometry: A Practical Guide, pp. 2-13, Elsevier, Amsterdam, Netherlands, 2011.

[109] F. McLafferty, W. Fred, and Turecek, Interpretation of Mass Spectra, University Science Books, Mill Valley, CA, USA, 4th edition, 1993.

[110] D. E. Raynie, "Analyte derivatization as an important tool for sample preparation," LCGC North America, vol. 36, pp. 14-17, 2018.

[111] C. F. Poole, "Derivatization reactions for use with the electron-capture detector," Journal of Chromatography A, vol. 1296, pp. 15-24, 2013.

[112] C. F. Poole, "Alkylsilyl derivatives for gas chromatography," Journal of Chromatography A, vol. 1296, pp. 2-14, 2013.

[113] A. C. Scott, R. F. Young, and P. M. Fedorak, "Comparison of GC-MS and FTIR methods for quantifying naphthenic acids in water samples," Chemosphere, vol. 73, no. 8, pp. 1258-1264, 2008.

[114] J. M. Gutierrez-Villagomez, J. Vázquez-Martínez, E. Ramírez-Chávez, J. Molina-Torres, and V. L. Trudeau, "Analysis of naphthenic acid mixtures as pentafluorobenzyl derivatives by gas chromatography-electron impact mass spectrometry," Talanta, vol. 162, pp. 440-452, 2017.

[115] S. Zan, J. Wang, F. Wang, Y. Han, M. Du, and J. Fan, "Variation and distribution of naphthenic acids in Dalian Bay sediment," Marine Pollution Bulletin, vol. 140, pp. 597-602, 2019.

[116] W. Jie, X. Cao, L. Chai, J. Liao, Y. Huang, and X. Tang, "Quantification and characterization of naphthenic acids in soils from oil exploration areas in China by GC/MS," $A n$ alytical Methods, vol. 7, no. 5, pp. 2149-2154, 2015.

[117] M. Merlin, S. E. Guigard, and P. M. Fedorak, "Detecting naphthenic acids in waters by gas chromatography-mass spectrometry," Journal of Chromatography A, vol. 1140, no. 1-2, pp. 225-229, 2007.

[118] J. M. Gutierrez-Villagomez, J. Vázquez-Martínez, E. Ramírez-Chávez, J. Molina-Torres, and V. L. Trudeau, "Profiling low molecular weight organic compounds from naphthenic acids, acid extractable organic mixtures, and oil sands process-affected water by SPME-GC-EIMS," Journal of Hazardous Materials, vol. 390, Article ID 122186, 2020.

[119] D. Jones, C. E. West, A. G. Scarlett, R. A. Frank, and S. J. Rowland, "Isolation and estimation of the "aromatic" naphthenic acid content of an oil sands process-affected water extract," Journal of Chromatography A, vol. 1247, pp. 171-175, 2012.

[120] X. Ortiz, K. J. Jobst, E. J. Reiner et al., "Characterization of naphthenic acids by gas chromatography-fourier transform ion cyclotron resonance mass spectrometry," Analytical Chemistry, vol. 86, no. 15, pp. 7666-7673, 2014.

[121] M. P. Barrow, K. M. Peru, and J. V. Headley, "An added dimension: GC atmospheric pressure chemical ionization FTICR MS and the athabasca oil sands," Analytical Chemistry, vol. 86, no. 16, pp. 8281-8288, 2014.

[122] L. W. Hantao, B. R. Toledo, and F. Augusto, "Fases estacionárias de líquidos iônicos em cromatografia gasosa: fundamentos, avanços recentes e perspectivas," Quimica Nova, vol. 39, pp. 81-93, 2016.

[123] M. Adahchour, J. Beens, R. J. J. Vreuls, and U. A. T. Brinkman, "Recent developments in comprehensive two-dimensional gas chromatography $(\mathrm{GC} \times \mathrm{GC}), " \operatorname{Tr} A C$ Trends in Analytical Chemistry, vol. 25, no. 5, pp. 438-454, 2006.

[124] J. Beens, H.-G. Janssen, M. Adahchour, and U. A. T. Brinkman, "Flow regime at ambient outlet pressure and its influence in comprehensive two-dimensional gas chromatography," Journal of Chromatography A, vol. 1086, no. 1-2, pp. 141-150, 2005.

[125] M. P. Pedroso, L. Antonio, F. De Godoy et al., "Cromatografia gasosa bidimensional abrandente (GCxGC)," Quimica Nova, vol. 32, pp. 421-430, 2009.

[126] C. Hao, J. V. Headley, K. M. Peru, R. Frank, P. Yang, and K. R. Solomon, "Characterization and pattern recognition of oil-sand naphthenic acids using comprehensive two-dimensional gas chromatography/time-of-flight mass spectrometry," Journal of Chromatography A, vol. 1067, no. 1-2, pp. 277-284, 2005.

[127] S. K. Lengger, A. G. Scarlett, C. E. West, and S. J. Rowland, "Diamondoid diacids ('O4' species) in oil sands processaffected water," Rapid Communications in Mass Spectrometry, vol. 27, no. 23, pp. 2648-2654, 2013.

[128] S. J. Rowland, C. E. West, A. G. Scarlett, D. Jones, and R. A. Frank, "Identification of individual tetra- and pentacyclic naphthenic acids in oil sands process water by comprehensive two-dimensional gas chromatography/mass spectrometry," Rapid Communications in Mass Spectrometry, vol. 25, no. 9, pp. 1198-1204, 2011.

[129] S. J. Rowland, C. E. West, A. G. Scarlett, and D. Jones, "Identification of individual acids in a commercial sample of naphthenic acids from petroleum by two-dimensional comprehensive gas chromatography/mass spectrometry," Rapid Communications in Mass Spectrometry, vol. 25, no. 12, pp. 1741-1751, 2011.

[130] S. J. Rowland, C. E. West, A. G. Scarlett et al., "Monocyclic and monoaromatic naphthenic acids: synthesis and characterisation," Environmental Chemistry Letters, vol. 9, no. 4, pp. 525-533, 2011.

[131] S. J. Rowland, C. E. West, A. G. Scarlett, C. Ho, and D. Jones, "Differentiation of two industrial oil sands process-affected waters by two-dimensional gas chromatography/mass spectrometry of diamondoid acid profiles," Rapid Communications in Mass Spectrometry, vol. 26, no. 5, pp. 572-576, 2012.

[132] F. C. Damasceno, L. D. A. Gruber, A. M. Geller et al., "Characterization of naphthenic acids using mass spectroscopy and chromatographic techniques: study of technical mixtures," Analytical Methods, vol. 6, no. 3, pp. 807-816, 2014.

[133] D. T. Bowman, G. F. Slater, L. A. Warren, and B. E. McCarry, "Identification of individual thiophene-, indane-, tetralin-, cyclohexane-, and adamantane-type carboxylic acids in composite tailings pore water from Alberta oil sands," Rapid Communications in Mass Spectrometry, vol. 28, no. 19, pp. 2075-2083, 2014.

[134] C. E. West, J. Pureveen, A. G. Scarlett et al., "Can two-dimensional gas chromatography/mass spectrometric identification of bicyclic aromatic acids in petroleum fractions help to reveal further details of aromatic hydrocarbon biotransformation pathways?" Rapid Communications in Mass Spectrometry, vol. 28, no. 9, pp. 1023-1032, 2014.

[135] D. T. Bowman, L. A. Warren, and G. F. Slater, "Isomerspecific monitoring of naphthenic acids at an oil sands pit lake by comprehensive two-dimensional gas 
chromatography-mass spectrometry," The Science of the Total Environment, vol. 746, Article ID 140985, 2020.

[136] P. Hemström and K. Irgum, "Hydrophilic interaction chromatography," Journal of Separation Science, vol. 29, pp. 1784-1821, 2006.

[137] M. S. Ross, A. d. S. Pereira, J. Fennell et al., "Quantitative and qualitative analysis of naphthenic acids in natural waters surrounding the canadian oil sands industry," Environmental Science \& Technology, vol. 46, no. 23, pp. 1279612805, 2012.

[138] M. B. Woudneh, M. Coreen Hamilton, J. P. Benskin, G. Wang, P. McEachern, and J. R. Cosgrove, "A novel derivatization-based liquid chromatography tandem mass spectrometry method for quantitative characterization of naphthenic acid isomer profiles in environmental waters," Journal of Chromatography A, vol. 1293, pp. 36-43, 2013.

[139] C. F. Klitzke, Y. E. Corilo, K. Siek, J. Binkley, J. Patrick, and M. N. Eberlin, "Petroleomics by ultrahigh-resolution timeof-flight mass spectrometry," Energy \& Fuels, vol. 26, no. 9, pp. 5787-5794, 2012.

[140] X. Wang and K. L. Kasperski, "Analysis of naphthenic acids in aqueous solution using HPLC-MS/MS," Analytical Methods, vol. 2, no. 11, pp. 1715-1722, 2010.

[141] M. Gamal El-Din, H. Fu, N. Wang et al., "Naphthenic acids speciation and removal during petroleum-coke adsorption and ozonation of oil sands process-affected water," The Science of the Total Environment, vol. 409, no. 23, pp. 5119-5125, 2011.

[142] S. Samanipour, M. J. Reid, J. T. Rundberget, T. K. Frost, and K. V. Thomas, "Concentration and distribution of naphthenic acids in the produced water from offshore Norwegian north sea oilfields," Environmental Science \& Technology, vol. 54, no. 5, pp. 2707-2714, 2020.

[143] B. Wang, Y. Wan, Y. Gao et al., "Occurrences and behaviors of naphthenic acids in a petroleum refinery wastewater treatment plant," Environmental Science \& Technology, vol. 49, no. 9, pp. 5796-5804, 2015.

[144] C. Yang, G. Zhang, M. Serhan et al., "Characterization of naphthenic acids in crude oils and refined petroleum products," Fuel, vol. 255, Article ID 115849, 2019.

[145] C. Ajaero, K. M. Peru, M. Simair et al., "Fate and behavior of oil sands naphthenic acids in a pilot-scale treatment wetland as characterized by negative-ion electrospray ionization Orbitrap mass spectrometry," The Science of the Total Environment, vol. 631-632, pp. 829-839, 2018.

[146] A. S. Pereira, S. Bhattacharjee, and J. W. Martin, "Characterization of oil sands process-affected waters by liquid chromatography orbitrap mass spectrometry," Environmental Science \& Technology, vol. 47, no. 10, pp. 5504-5513, 2013.

[147] A. S. Pereira, M. S. Islam, M. Gamal El-Din, and J. W. Martin, "Ozonation degrades all detectable organic compound classes in oil sands process-affected water; an application of high-performance liquid chromatography/obitrap mass spectrometry," Rapid Communications in Mass Spectrometry, vol. 27, no. 21, pp. 2317-2326, 2013.

[148] S. J. Rowland, A. S. Pereira, J. W. Martin et al., "Mass spectral characterisation of a polar, esterified fraction of an organic extract of an oil sands process water," Rapid Communications in Mass Spectrometry, vol. 28, no. 21, pp. 2352-2362, 2014.

[149] R. P. Rodgers, T. M. Schaub, and A. G. Marshall, "Petroleomics: MS returns to its roots," Analytical Chemistry, vol. 77, pp. 20-27, 2005.
[150] M. Ghaste, R. Mistrik, and V. Shulaev, "Applications of fourier transform ion cyclotron resonance (FT-ICR) and orbitrap based high resolution mass spectrometry in metabolomics and lipidomics," International Journal of Molecular Sciences, vol. 17, no. 6, p. 816, 2016.

[151] J. V. Headley, K. M. Peru, A. Janfada, B. Fahlman, C. Gu, and S. Hassan, "Characterization of oil sands acids in plant tissue using Orbitrap ultra-high resolution mass spectrometry with electrospray ionization," Rapid Communications in Mass Spectrometry, vol. 25, no. 3, pp. 459-462, 2011.

[152] E. M. Schmidt, M. A. Pudenzi, J. M. Santos et al., "Petroleomics via Orbitrap mass spectrometry with resolving power above 1000000 at m/z 200," RSC Advances, vol. 8, no. 11, pp. 6183-6191, 2018.

[153] G. Vanini, T. A. Barra, L. M. Souza et al., "Characterization of nonvolatile polar compounds from Brazilian oils by electrospray ionization with FT-ICR MS and orbitrap-MS," Fuel, vol. 282, Article ID 118790, 2020.

[154] M. M. Mapolelo, R. P. Rodgers, G. T. Blakney, A. T. Yen, S. Asomaning, and A. G. Marshall, "Characterization of naphthenic acids in crude oils and naphthenates by electrospray ionization FT-ICR mass spectrometry," International Journal of Mass Spectrometry, vol. 300, no. 2-3, pp. 149-157, 2011.

[155] M. P. Barrow, M. Witt, J. V. Headley, and K. M. Peru, "Athabasca oil sands process water: characterization by atmospheric pressure photoionization and electrospray ionization Fourier transform ion cyclotron resonance mass spectrometry," Analytical Chemistry, vol. 82, no. 9, pp. 3727-3735, 2010.

[156] A. Nyakas, J. Han, K. M. Peru, J. V. Headley, and C. H. Borchers, "Comprehensive analysis of oil sands processed water by direct-infusion fourier-transform ion cyclotron resonance mass spectrometry with and without offline UHPLC sample prefractionation," Environmental Science \& Technology, vol. 47, no. 9, pp. 4471-4479, 2013.

[157] D. C. Palacio Lozano, J. A. Orrego-Ruiz, R. Cabanzo Hernández, J. E. Guerrero, and E. Mejía-Ospino, "APPI(+)FTICR mass spectrometry coupled to partial least squares with genetic algorithm variable selection for prediction of API gravity and CCR of crude oil and vacuum residues," Fuel, vol. 193, pp. 39-44, 2017.

[158] K. A. P. Colati, G. P. Dalmaschio, E. V. R. De Castro, A. O. Gomes, B. G. Vaz, and W. Romão, "Monitoring the liquid/liquid extraction of naphthenic acids in brazilian crude oil using electrospray ionization FT-ICR mass spectrometry (ESI FT-ICR MS)," Fuel, vol. 108, pp. 647-655, 2013.

[159] H. A. Alharbi, G. D. Morandi, P. D. Jones, S. B. Wiseman, and J. P. Giesy, "Comparison of the effects of extraction techniques on mass spectrometry profiles of dissolved organic compounds in oil sand process-affected water," Energy \& Fuels, vol. 33, no. 8, pp. 7001-7008, 2019.

[160] J. V. Headley, K. M. Peru, B. Fahlman, A. Colodey, and D. W. McMartin, "Selective solvent extraction and characterization of the acid extractable fraction of Athabasca oils sands process waters by Orbitrap mass spectrometry," International Journal of Mass Spectrometry, vol. 345-347, pp. 104-108, 2013.

[161] L. A. Terra, P. R. Filgueiras, R. C. L. Pereira et al., "Prediction of total acid number in distillation cuts of crude oil by ESI(-) FT-ICR MS coupled with chemometric tools," Journal of the Brazilian Chemical Society, vol. 28, pp. 1822-1829, 2017. 